\section{Resúmenes de Trabajos Libres}

Free Papers Abstracts

Resumo dos Trabalhos Livres

Volumen medio plaquetario (VMP) como biomarcador de respuesta inflamatoria y su utilidad como indicador temprano de mortalidad en pacientes con COVID-19

Patiño Flores Jorge Luis, Hidalgo Martínez Sandra Margarita Hospital General Regional No. 1, Instituto Mexicano del

Seguro Social, Querétaro, Querétaro, México.

Antecedentes: La sepsis es una enfermedad mortal. Disfunción orgánica causada por una respuesta disregulada del huésped a un proceso infeccioso. El incremento del VMP se correlaciona con enfermedades inflamatorias. Tiene utilidad como marcador de trombosis y disfunción endotelial, como la sepsis. Es importante contar con marcadores que identifiquen de manera económica y de fácil acceso y predigan mortalidad en pacientes con COVID-19. Objetivo: Determinar el VMP como indicador temprano de mortalidad en pacientes con COVID-19. Material y métodos: Se realizó un estudio de cohorte, observacional, prospectivo, comparativo y longitudinal. Se tomó biometría hemática y hemocultivo. Se realizó una base de datos y se obtuvo la sensibilidad, especificidad, valor predictivo positivo, valor predictivo negativo y factor de máxima verosimilitud. Resultados: Un VMP $\geq 7.4 \mathrm{fL}$ aumentó 3.1 veces la mortalidad. Tuvo una sensibilidad de $62.2 \%$, especificidad de $69.6 \%$, VPP $57.5 \%$ VPN $69.6 \%$ y RVP de 1.79 . Conclusiones: La COVID-19 se comporta como una infección compleja que puede involucrar diversos órganos o sistemas en su anfitrión. Tras la destrucción de plaquetas inducida por estrés, la disminución del conteo plaquetario estimula aún más a los megacariocitos para que produzcan una gran cantidad de plaquetas, lo que conduce a un aumento del VMP.

Decúbito prono despierto en pacientes con falla respiratoria aguda hipoxémica inducida por COVID-19: ensayo clínico multicéntrico aleatorizado

Vargas Obieta Alexandra, Ibarra Estrada Miguel Ángel, Mijangos Méndez Julio César, Aguirre Ávalos Guadalupe Hospital Civil «Fray Antonio Alcalde».

Introducción: El decúbito prono en pacientes despiertos ha demostrado mejorar la oxigenación en pacientes con COVID-19; sin embargo, la eficacia y duración óptima para prevenir intubación son inciertas. Objetivos: Primario: intubación; secundario: mortalidad, estancia hospitalaria y efectos adversos a 28 días. Material y métodos: Ensayo clínico, aleatorizado, multicéntrico, abierto, incluyendo pacientes con diagnóstico de COVID-19 e insuficiencia respiratoria aguda hipoxémica en tratamiento con cánulas nasales de alto flujo. Se incluyeron 430 pacientes que fueron asignados a recibir prono despierto (216) o manejo estándar (214). Resultados: El grupo de intervención tuvo menor incidencia de intubación (30 vs 43\%, RR 0.70; IC95\% 0.54-0.90, p = 0.006), y estancia hospitalaria (11 vs 13 días, $\mathrm{p}=0.001)$. La mortalidad fue similar en ambos grupos $(p=0.37)$. Una duración $\geq 8$ horas en prono se asoció a mayor éxito al tratamiento (HR 21.6 [IC95\% 13.4-35.0]). No se presentaron efectos adversos serios y fueron similares en ambos grupos. Discusión: En pacientes con COVID-19 y falla respiratoria aguda hipoxémica en tratamiento con oxígeno en alto flujo, el prono despierto reduce la tasa de intubación y estancia hospitalaria. Los pacientes deberían permanecer en prono un mínimo de 8 horas al día hasta que se suspenda la terapia con alto flujo.
Acceso venoso central en pacientes de difícil canulación: ensayo clínico controlado aleatorizado

Cruz Muñoz Beatriz, Ibarra Estrada Miguel Ángel, Aguirre Ávalos Guadalupe, Mijangos Méndez Julio César, Rodríguez Barajas Leonardo Giovanni Unidad de Cuidados Intensivos, Hospital Civil de Guadalajara «Fray Antonio Alcalde».

Introducción: Se recomienda que la canulación de venas centrales guiada por ultrasonido sea preferentemente en venas yugulares internas; sin embargo, éstas tienden a presentar colapso en diferentes escenarios clínicos como hipotensión, ansiedad, diaforesis o ventilación mecánica. Objetivos: Comparar la tasa de éxito en canulación guiada por ultrasonido de diferentes venas centrales en pacientes con colapso espontáneo de yugulares. Material y métodos: Ensayo clínico aleatorizado, en el que se incluyeron pacientes con requerimiento de catéter central y presencia de colapsabilidad espontánea de venas yugulares a la evaluación por ultrasonido. Resultados: En 252 pacientes con colapsabilidad de yugulares promedio de $49 \%$, la tasa más alta de éxito al primer intento fue para innominada (81/84 [96\%]), seguido de subclavia (75/84 [89\%]) y yugular (64/84 [76\%]), $(\mathrm{p} \leq 0.0001)$. En comparación a la innominada y subclavia, se calculó un RR de $1.22(p=0.0003)$ para fallo hasta tres intentos en vena yugular. Una colapsabilidad $\geq 75 \%$ en yugular predice falla con sensibilidad de $98 \%$ y especificidad de $94 \%$. El sexo, edad, IMC, ventilación mecánica, diámetro del cuello o marcas anatómicas visibles no se asociaron de forma independiente al éxito. Discusión: En pacientes con colapso espontáneo de venas yugulares, las innominadas son una mejor opción para canulación venosa central.

La variante Birolleau, ¿un signo ultrasonográfico poco reconocido? Novelo Pérez José Patricio, Dávila Zárate Josué Isaí, Pinedo Lechuga Marcela

Unidad Médica de Alta Especialidad del IMSS, UMAE 25. Monterrey, Nuevo León.

Introducción: La ultrasonografía permite abordar un amplio diagnóstico diferencial ante datos clínicos de insuficiencia respiratoria aguda, por medio de la integración de diferentes patrones y artefactos en relación con el parénquima pulmonar. Caso clínico: Varón hispano de 56 años con antecedente de adenocarcinoma de colon avanzado. Se ingresó por absceso abdominal. Tras cinco días de hospitalización, presentó disnea severa con uso de músculos accesorios de la respiración más hipoxemia grave refractaria; se documentaron zonas hiperecoicas y homogéneas bilaterales por insonación pulmonar. A pesar del tratamiento médico oportuno, el paciente tuvo un desenlace fatal. Discusión: El caso presentado desarrolló insuficiencia respiratoria severa súbita que ameritó uso de ventilación mecánica invasiva. Se evidenció daño pulmonar por ultrasonido. La variante Birolleau se caracteriza por la presencia de zonas hiperecoicas y homogéneas produciendo un «pulmón blanco», signo ultrasonográfico compatible con edema agudo de pulmón cardiogénico y no cardiogénico. Conclusión: El síndrome intersticial por ultrasonografía se visualiza en diferentes grados de lesión pulmonar, siendo el edema agudo de pulmón la etiología más grave. Se desconocen los factores de riesgo asociados para la aparición de este signo ultrasonográfico.

\section{Características epidemiológicas y curso clínico de pacientes} con neumonía por SARS-CoV-2 en el Hospital General de Puebla «Dr. Eduardo Vázquez Navarro» de marzo 2020-marzo 2021 Ortega Vargas José Luis, Hernández Morales María del Rocío Hospital General de Puebla «Dr. Eduardo Vázquez Navarro». 
Introducción: EI SARS-CoV-2 es una enfermedad emergente, y tener poco conocimiento del virus lo vuelve un grave problema de salud. México no es la excepción, por lo que es de suma importancia que cada estado de la República Mexicana cuente con estudios epidemiológicos de su propia población. Objetivo: Describir las características epidemiológicas y curso clínico de pacientes con Neumonía por SARS-CoV-2 en el Hospital General del Sur Puebla «Dr. Eduardo Vázquez Navarro» en el periodo marzo 2020 a marzo 2021. Material y métodos: Estudio observacional, ambispectivo y descriptivo. Se incluyeron pacientes adultos con neumonía por SARS-CoV-2 por PCR y TC de tórax del Servicio de Medicina Interna del HGS. Resultados: La frecuencia de neumonía por SARS-CoV-2 fue de 7\%, de los 127 pacientes incluidos, 33 presentaron enfermedad no grave comparado con 94 con enfermedad grave, 75 pacientes $(59.1 \%)$ fueron hombres y 52 mujeres (40.9\%). La edad promedio fue 55 años ( \pm 13.76$)$. Las comorbilidades más importantes fueron: HAS, DT2 y obesidad. Los síntomas más comunes fueron: disnea $(85.8 \%)$ y fiebre $(70.6 \%)$, seguidos de ataque al estado general (67.7\%) y tos (59.1), $93.7 \%$ de los pacientes necesitaron oxigenoterapia, $44.9 \%$ mascarilla bolsa reservorio y $27.6 \%$ recibieron ventilación mecánica invasiva. Los pacientes que fallecieron fueron de $49.6 \%$ y los que vivieron $50.4 \%$. Se categorizó como COVID-19 grave y no grave, y se realizó un cálculo de $\chi^{2}$ para evaluar si había diferencias significativas entre las variables en ambos grupos, donde sólo se observa para la variable dímero $\mathrm{D}$ una $p=0.014$. Conclusión: La mortalidad de los pacientes críticamente enfermos con neumonía por SARS-CoV-2 es alta. Ciertos pacientes, aquellos del género masculino, de 40 a 60 años, con HAS, DT2 y obesidad, se encontraban en una condición crítica al ingreso y progresaron rápidamente hasta la muerte dentro de las dos a tres semanas desde el inicio de la enfermedad.

Asociación de biomarcadores inflamatorios iniciales con pronóstico en pacientes COVID-19 bajo ventilación mecánica invasiva en el Departamento de Medicina Crítica «Dr. Mario Shapiro»

Gómez-de-Segura González Daniel,

Pedraza Montenegro Axel, Fuentes Gómez Arturo Javier, Aguirre Sánchez Janet Silvia, Chaires Gutiérrez Rodrigo Centro Médico ABC.

Introducción: La relación de biomarcadores inflamatorios con el pronóstico de los pacientes COVID-19 en ventilación mecánica es un punto atractivo para la toma de decisiones. No se ha descrito en población mexicana o dentro de la terapia intensiva el impacto que tienen. Objetivo: Describir la relación que tienen los biomarcadores iniciales con el pronóstico de pacientes COVID-19 en ventilación mecánica invasiva (VMI). Material y métodos: Estudio retrospectivo, longitudinal de marzo a septiembre de 2020. Se relacionaron los niveles de Interleucina-6, dímero $D$, proteína $C$ reactiva (PCR), procalcitonina (PCT) y ferritina al ingreso de pacientes COVID-19 en VMI con la mortalidad, APACHE-II, SAPS-II y SOFA al ingreso, días de ventilación y estancia hospitalaria. Resultados: Se estudiaron 141 pacientes con $17.1 \%$ de mortalidad. Niveles elevados de PCT y PCR se relacionaron con menor distensibilidad del sistema respiratorio $(<$ $30 \mathrm{~mL} / \mathrm{cmH}_{2}$ O) y mayor SOFA/SAPS-II. Más de tres biomarcadores elevados se asoció con mortalidad, días de estancia hospitalaria, días en terapia intensiva y días de ventilación mecánica. Discusión: Los biomarcadores iniciales se relacionaron de forma directa con la gravedad del cuadro y la mortalidad durante la evolución.

Índice de eficiencia ventilatoria como factor pronóstico en pacientes con ventilación mecánica con SARS-CoV-2

Márquez Martínez Alejandra Michelle

Hospital General "La Villa", Ciudad de México.

La infección pandémica actual por COVID-19 es causada por SARSCoV-2. El énfasis en la ventilación mecánica se ha centrado en mejorar la oxigenación, evitando al mismo tiempo complicaciones ia- trogénicas. Aunque las mediciones de $\mathrm{CO}_{2}$ se utilizan para guiar la adecuación ventilatoria, la mayoría de las estrategias están dirigidas a una oxigenación adecuada. Demostrar que el índice de eficiencia ventilatoria (IEV) es un marcador pronóstico en pacientes con VM con SARS-COV-2. Se realizó un estudio retrospectivo, analítico de casos y controles, incluyendo 106 pacientes, entre 18-90 años ingresados a UCI, con neumonía por SARS-CoV-2, 2 y t de Student. El procesamiento de resultados para la estadística descriptiva y analítica, se realizaron con SPSS. Del total, $72 \%$ fueron mujeres, $28 \%$ hombres con una media de edad de 50.1 años. Se analizó mediante regresión logística binaria la relación entre la mortalidad e IEV al ingreso y 24 horas, y el índice de Kirby. Encontrándose que el IEV (OR = 4.7 [IC95\%, 1.407-4.738], $\mathrm{p}=0.002)$ y éste a las 24 horas (OR $=16.8$ [IC95\%, 5.758-49.022], $\mathrm{p}=0.00$ ) se asocian de forma independiente con la mortalidad.

Asociación entre mortalidad y sangrado mayor (SM) en pacientes con ventilación mecánica (VM) y COVID-19 en el Departamento de Medicina Crítica «Dr. Mario Shapiro» Ángeles Márquez Mónica, Aisa Álvarez Alfredo, Montaño Alejandro, Aguirre Sánchez Janet Silvia, Chaires Gutiérrez Rodrigo Centro Médico ABC.

Introducción: El COVID-19 se asocia con inflamación y estado protrombótico, la anticoagulación terapéutica se asoció con menor probabilidad de tromboembolia, pero probabilidad más alta de SM. Múltiples reportes indican que el SM en otras patologías se asocia con mayor mortalidad por cualquier causa. Objetivo: Determinar asociación entre SM y mortalidad en pacientes con COVID-19 en unidad de terapia intensiva (UTI). Material y métodos: Se realizó un estudio de cohorte retrospectiva de marzo a agosto de 2020 en pacientes de UTI con COVID-19 y VM, se comparó la mortalidad de los pacientes con SM y el resto de la población. Se utilizó STATA para el análisis estadístico, mediante prueba exacta de Fisher, $\chi^{2}$, test de Wilcoxon y regresión de Cox. Resultados: De 134 pacientes, 99\% recibió anticoagulación terapéutica, $24 \%$ murieron, $13 \%$ presentó SM, la mortalidad en SM fue de $38 \%$ frente a $15.7 \%$ de los pacientes sin sangrado; sin embargo, no se encontró asociación entre la presencia de SM y mortalidad HR 1.54, IC (0.56-4.22) p = 0.84. Conclusión: En este estudio se demostró que no existe asociación entre mortalidad y sangrado mayor, contrario a lo que se encuentra descrito en otras patologías.

Caracterización del paciente anciano crítico con politrauma Hernández López Guillermo David,

Gorordo Delsol Luis Antonio, Escobar Ortiz Diana

Hospital de Traumatología, Magdalena de las Salinas. IMSS.

Introducción: El trauma constituye una causa importante de incapacidad y muerte, pero su impacto es diferente en los distintos grupos de edad. El deterioro fisiológico y las enfermedades crónicas que afectan a los ancianos son responsables del aumento en la morbimortalidad. Objetivo: Caracterizar los pacientes ancianos críticos con politrauma. Material y métodos: Estudio observacional, descriptivo, longitudinal en 26 pacientes ancianos con politrauma. Resultados: Se encontró predominio de pacientes masculinos (53.8\%), con edad promedio de 76 años. Los principales traumatismos fueron el de tórax (96.1\%), abdomen $(30.7 \%)$ y TCE $(100 \%)$; seis pacientes requirieron craniectomía. El tiempo de evolución desde el momento del accidente al ingreso a UCl fue mayor de seis horas en $50 \%$ de los casos; los procedimientos más frecuentes fueron el uso de fármacos vasoactivos $(80.76 \%)$, ventilación mecánica $(96.1 \%)$ y terapia de reemplazo renal (3.8\%). Glasgow de ingreso menor de 9 (84.46\%). La mortalidad fue de $57.6 \%$, las causas identificadas del trauma fueron: caídas $(65.3 \%)$, accidente automotor $(30.7 \%$ ) y agresión por terceras personas (3.8\%), el promedio de estancia fue de 12.86 días. Discusión: En los adultos mayores el politraumatismo está mayormente relacionado con caídas, aquellos con TCE experimentan una mayor morbilidad y mortalidad. 
Calidad de vida relacionada a la salud en sobrevivientes de COVID-19 grave y factores de riesgo asociados

Tamayo Pérez Dulce Mariana, Baltazar Torres José Ángel, Rivero Sigarroa Eduardo

Instituto Nacional de Ciencias Médicas y Nutrición «Salvador Zubirán».

Introducción: Veinte por ciento de pacientes con COVID-19 desarrollan la forma grave y pueden ingresar a terapia intensiva ( $\mathrm{Tl})$. Poco se sabe acerca de la calidad de vida relacionada a la salud (CVRS) en estos enfermos. Objetivo: Conocer la CVRS en sobrevivientes de COVID-19 grave a seis meses del egreso de TI. Material y métodos: Estudio retrospectivo en pacientes con COVID-19 grave ingresados a TI. Recabamos variables demográficas y clínicas. Medimos CVRS a seis meses del egreso de TI mediante SF-36. Las variables numéricas se expresan como promedio/desviación estándar o mediana/rango intercuartil y las nominales como porcentaje. Resultados: Analizamos 93 pacientes, $67.7 \%$ hombres, edad media 52.4 años, $68.8 \%$ estuvieron en prono, la duración media de la ventilación mecánica fue de 13 días, la estancia en TI de 16 días y en el hospital de 24 días. La media de la calificación en escala SF-36 fue de 81.8 , del componente físico de 76.4 y del mental de $87.2,10.8 \%$ de los pacientes tuvieron mala calidad de vida global, $23.6 \%$ en el componente físico y $12.9 \%$ en el mental. Discusión: COVID-19 tiene mayor impacto en el componente físico de la CVRS a los seis meses de egreso de $\mathrm{TI}$.

Relación inversa albúmina-globulina como predictor de severidad en pacientes de $\mathrm{UCl}$ con diagnóstico por infección por neumonía por SARS-CoV-2

Sergio Arturo Cano Gutiérrez, Martín Mendoza Rodríguez, José Alfredo Cortes Munguía

Hospital General "La Villa», Secretaría de Salud de la Ciudad de México.

Introducción: En México, el 9 de enero de 2020, la Dirección General de Epidemiología emitió un aviso preventivo sobre la pandemia de COVID-19. En situaciones de estrés, la síntesis de albúmina decrece y es un indicador del estado de estrés del paciente y no sólo indicador del estado nutricional. Objetivo: Demostrar que la relación inversa albúmina-globulina sirve como predictor de severidad en neumonía grave por COVID-19. Material y métodos: Se revisaron 120 expedientes idóneos durante el periodo de septiembre de 2020 a mayo de 2021. Se utilizó la correlación de Pearson para el análisis estadístico. Resultados: Ochenta y tres por ciento correspondió al género masculino y $17 \%$ al femenino de la población en estudio. La edad promedio fue de 42 años. La albúmina promedio de ingreso fue de $3.11 \mathrm{mg} /$ $\mathrm{dL}$, a las 72 horas de $2.59 \mathrm{mg} / \mathrm{dL}$, en tanto la globulina a su ingreso fue de 2.56 y las 72 horas fue de $2.61 \mathrm{mg} / \mathrm{dL}$. La ventilación mecánica estuvo presente en $91 \%$ de la población. Discusión: La relación 1:2 fue la proporción con mayor riesgo de mortalidad asociado a infección por COVID-19, en tanto, el factor de riesgo asociado a severidad fue de origen metabólico como la diabetes.

Evaluación ultrasonográfica del diafragma en el enfermo grave con mielopatía espondilótica cervical

Hernández López Guillermo David, Escobar Ortiz Diana, Gorordo Delsol Luis Antonio, Gasca Aldama José Carlos, Cerón Juárez Raúl Hospital de Ortopedia «Magdalena de las Salinas", IMSS.

Introducción: Aproximadamente $10 \%$ de todos los pacientes de 55 años o más presentan mielopatía espondilótica cervical clínica, mientras que $85 \%$ de los adultos mayores de 60 años presentan espondilosis cervical radiográfica. El ultrasonido es un método simple, no invasivo, y a la cabecera del enfermo, que evalúa los movimientos diafragmáticos normales y sus principales alteraciones. Objetivo: Reportar las alteraciones en la cinética diafragmática en el paciente con mielopatía espondilótica cervical en estado crítico. Material y métodos: Se incluyeron todos los pacientes que ingresaron a la $\mathrm{UCl}$ con diagnóstico de mielopatía espondilótica cervical, mayores de 18 años, ambos sexos. Resultados: Se incluyeron 41 pacientes con edad promedio 68.1 años; $63.41 \%$ con nivel de afectación en C3; $9.75 \%$ en clase 5 de Nurick. Diez pacientes presentaron alteraciones en la función del diafragma y requirieron más días de ventilación mecánica y estancia en UCI. Discusión. La identificación y predicción de pacientes con desconexión dificultosa es de gran importancia en la práctica clínica. El uso de la ecografía en la evaluación de la cinética diafragmática en el paciente crítico con mielopatía espondilótica, nos permite guiar el diagnóstico y tratamiento de pacientes con alteraciones de la cinética diafragmática.

Características clínicas de las pacientes con enfermedad hipertensiva del embarazo admitidas en la Unidad de Cuidados Intensivos de un Hospital de Segundo Nivel de Atención Hernández López Guillermo David, Estrada Carreón Marisela, Ocejo Jiménez Víctor Hugo, Luna Cuéllar Antonio,

Valenzuela Plata Alfredo

Hospital General Atizapán, ISEM.

Introducción: El manejo de pacientes obstétricas críticamente enfermas en la UCl es un desafío debido a su fisiología alterada. Objetivo: Caracterizar las pacientes obstétricas críticamente enfermas asistidas en la unidad de cuidados intensivos. Material y métodos: Estudio descriptivo, retrospectivo en el que analizamos las características clínicas, complicaciones, severidad y supervivencia materna en gestantes con preeclampsia grave que requirieron ingreso a la UCl. Se analizaron las características asociadas a la morbilidad materna y la mortalidad asociada a la misma. Resultados: Se incluyeron 32 pacientes edad promedio 27.2 años con diagnóstico de enfermedad hipertensiva del embarazo y cumplieron criterios de severidad. Se observó mayor número de casos con preeclampsia $(75 \%)$ que de eclampsia (6.25\%). En más de $80 \%$ de los casos se interrumpió el embarazo vía cesárea. Las manifestaciones clínicas más frecuentes fueron, cefalea, epigastralgia, acúfenos y dolor en hipocondrio derecho. El perfil pulmonar predominante fue el $B$ en $53.1 \%$ de los casos; $41 \%$ presentó obesidad. $10 \%$ requirió ventilación mecánica, y en un caso terapia sustitutiva renal. La mortalidad fue de $6.25 \%$. Discusión: El manejo de pacientes obstétricas críticamente enfermas en la UCl es un desafío debido a su fisiología alterada. Se recomienda un abordaje sistemático para mejorar los resultados.

Procalcitonina y proteína $\mathrm{C}$ reactiva como biomarcadores predictores de severidad en los pacientes con neumonía por SARS-CoV-2 en la UCI Moreno Rodríguez Irma Julieta, Mendoza Rodríguez Martín Hospital General «La Villa» (HGLV).

La enfermedad por COVID-19 es un trastorno multisistémico que surgió en diciembre de 2019 y se convirtió rápidamente en carga mundial como pandemia el 11 de marzo. Dentro de los marcadores en esta patología se encuentran los de inflamación como los hematológicos y las concentraciones de moléculas en sangre: Dímero D, proteína $\mathrm{C}$ reactiva y procalcitonina. Siendo predictores independientes de severidad y mortalidad por SARS-CoV-2. Este estudio se realizó en el Hospital General «La Villa» de la Secretaría de Salud de la Ciudad de México durante el primer semestre del 2021. Los datos en expedientes de la muestra fueron procesados con un análisis estadístico descriptivo de variables cualitativas. El proceso estadístico se realizó con curvas ROC y área bajo la curva de PCT y PCR para predecir severidad y mortalidad. Como pruebas inferenciales se aplicó $\chi^{2}$. Se detectó para la PCT utilizada como marcador de predicción de severidad, una sensibilidad de $80 \%$, especificidad de $65 \%$ y proteína $C$ reactiva con una sensibilidad de $80 \%$, especificidad de $60 \%$. La procalcitonina y la proteína $\mathrm{C}$ reactiva han demostrado tener la capacidad de predicción de gravedad en el paciente con infección por el virus SARS-CoV-2, con una sensibilidad de $80 \%$ en pacientes catalogados como graves. 
Microorganismos asociados a infección de pacientes con SARS-CoV-2 y su impacto pronóstico en UCI

López Torres Fabiola

Hospital General "La Villa». Secretaría de Salud de la Ciudad de México.

Introducción: La mortalidad por SARS-COV-2 es elevada, relacionada con las comorbilidades, sobreinfecciones bacterianas, nosocomiales y/o asociadas a la ventilación mecánica. Objetivos: Conocer el tipo de gérmenes más comunes asociados a sobreinfección de pacientes con SARS-CoV-2, los días de estancia y las comorbilidades asociadas. Metodología: Estudio descriptivo, longitudinal, ambispectivo. Incluyó todos los pacientes hospitalizados con diagnóstico COVID-19 de la UCI del Hospital General «La Villa» con toma y resultado de cultivos del 1 de septiembre de 2020 al 31 de mayo de 2021 y se realizó un análisis de los principales microorganismos asociados. Resultados: Total 85 pacientes con COVID-19 con cultivos, la mediana de edad fue 50 años, $74.1 \%$ hombres y $25.9 \%$ mujeres; $60 \%$ obesos, $55.3 \%$ hipertensos, $48.2 \%$ DM2; $9.4 \%$ con patología pulmonar de base y $3.5 \%$ VIH positivo. El $84.7 \%$ recibió antibiótico inicial, $64.7 \%$ cultivos positivos bacterias y $12.9 \%$ hongos (C. albicans), los principales microorganismos: Acinetobacter baumannii (25.9\%), E. coli $(10.6 \%)$ y S. epidermidis (5.9\%). La mediana de estancia en UCI fue seis días, con máximo de 43. Los pacientes con ventilación mecánica tuvieron estancia más prolongada, con una mediana de 10 días, mínimo 1 y máximo de 43. La mediana de tiempo intubado fue seis días, máximo 26 . La mortalidad fue de $65.9 \%$ (56/85).

\section{Correlación volumen plaquetario medio con necesidad de} apoyo MV y mortalidad en pacientes con SARS-CoV-2

Vázquez Cortés César Enrique

Hospital General de La Villa. SS de la Ciudad de México.

VPM es indicador del tamaño y actividad de las plaquetas. Valores elevados reflejan un medio trombótico y puede asociarse a SARSCoV-2. Objetivo: El VPM predice necesidad de apoyo VM y mortalidad en SARS-CoV-2. Material y métodos: Estudio descriptivo, analítico, transversal y ambispectivo, que incluyó 44 pacientes. El procesamiento se realizó en Minitab Inc. Se aplicó prueba de $\chi^{2}$ para asociación. Prueba exacta de Fisher en casos correspondientes, y se obtuvo el valor de $\mathrm{V}^{2}$ de Cramer a fin de explorar la asociación entre los mismos. Para las asociaciones de variables continuas se exploraron mediante prueba $r$ de Pearson. Se realizó prueba ANOVA, se tomó como modelo el VPM y covariables como edad, sexo, resultados de días para VM y mortalidad. Resultados y discusión: Dieciséis hombres, 28 mujeres. LRA en $40.9 \%$, mortalidad de $93.18 \%$. La mediana del VPM al ingreso fue 9.8. Pacientes con LRA tienen una media de VPM de 10.3 vs 9.7 sin LRA. La asociación entre días de inicio de VM y días en UTI, con relación al VPM al ingreso y tomando covariables sexo y edad presentó valores de $p=0.433,0.100$ y 0.940 . EI VPM inicial no se asocia a mortalidad ni inicio de VM.

\section{Experiencia de la traqueostomía en pacientes} críticamente enfermos con COVID-19

Enriquez Barajas Christian Michel,

Vargas Obieta Alexandra, Chávez Peña Quetzalcóatl, Hernández Lugo David, Marín Rosales Miguel

Hospital Civil de Guadalajara «Fray Antonio Alcalde».

Introducción: Evidenciamos un aumento de los enfermos críticos con COVID-19 que requieren VMI prolongada. Hay incertidumbre sobre el papel de la traqueostomía para el destete de VMI en COVID-19 y la indicación clara del momento es variable. Objetivo: Describir la evolución bajo VMI y necesidad de traqueostomía, variables durante la estancia en la UCI y posibles complicaciones por COVID-19. Material y métodos: Estudio prospectivo observacional en UCI del HCGCOVID que requirió tratamiento ventilatorio a partir del 10 de julio al 10 de octubre de 2021. Resultados: Se realizaron 20 procedimientos, edad promedio 47 años, $65 \%$ masculino, $85 \%$ no vacunados, con un egreso de $\mathrm{UCl}$ de $70 \%$, sin diferencia estadística significativa entre tipo de procedimiento, días de VMI, días de BNM, PEEP, $\mathrm{FiO}_{2}$, estancia en $\mathrm{UCl}$, excepto diferencia en mortalidad en $\mathrm{UCl}$ significativa en relación al IK con una $p$ significativa de 0.012 . Discusión: La traqueostomía es un procedimiento de un éxito considerable para la progresión ventilatoria, el tiempo promedio de 14 días de VMI al momento de realizarse tiene una tendencia favorable, significativo en base al IK; sin embargo se necesita mayor número de pacientes. No se reportaron contagios en el personal.

Eficacia de quetiapina en pacientes con COVID-19 y psicosis activa en terapia intensiva Peña Carrillo Héctor, Nieva Vázquez Adriana,

Bravo Delgado Humberto Rafael, Peña Jiménez César Hospital Independencia, Tehuacán, Puebla.

Los pacientes en terapia intensiva de COVID-19 tienen riesgo de manifestar crisis psicóticas como desorientación y ansiedad, debido a factores como la hospitalización prolongada, mayoría de edad, aislamiento, hipoxemia, comorbilidades preexistentes y/o el politratamiento farmacológico que reciben. Además, la presencia sostenida de episodios ansiolíticos en un individuo puede repercutir y aumentar otros trastornos mentales como depresión, psicosis o alucinaciones. El objetivo del estudio fue evaluar la eficacia de la quetiapina a dosis inferiores de las terapéuticas. Se realizó un estudio prospectivo y longitudinal en 21 pacientes de la Unidad de Cuidados Intensivos del Hospital Independencia, Tehuacán, Puebla. Los pacientes recibieron dosis de $12.5 \mathrm{mg}$ de quetiapina cada ocho horas. Durante cinco días fueron evaluados en el primer, tercer y quinto día mediante los criterios RASS para medir sus niveles de agitación. Se observaron cambios a partir de un estado psicótico (escala 3 o 4) a un estado de sedación (escala -3 o -4) sin afectar el nivel de conciencia de estos pacientes. El presente estudio demostró que a dosis bajas de quetiapina se logra controlar las crisis psicóticas de pacientes en UCI con COVID19, siendo un tratamiento alternativo y no contraproducente para la mejora del paciente.

Asociación entre el balance hídrico positivo y el fracaso en la prueba de la ventilación espontánea en pacientes con ventilación mecánica invasiva

Hernández Ortega Hilda María, Esquivel Chávez Alejandro, Canedo Castillo Nancy Allin, Arteaga Méndez Cinthya Angélica, Zamora Varela Sergio

UMAE, Hospital de Especialidades "Dr. Antonio Fraga Mouret» CMN «La Raza».

Objetivo: Determinar si el $\mathrm{BH}$ en las últimas 24 horas está asociado con fracaso en la PVE en pacientes con VMI. Material y métodos: Estudio prospectivo, longitudinal, observacional y analítico en la UCl. Se calculó el BH en 24 horas. Se realizó PVE de al menos 30 minutos antes del retiro de la VM. Se formaron dos grupos; $\mathrm{BH}$ positivo y negativo, el punto de corte de BH se obtuvo a través de curva ROC, las variables con distribución paramétrica se reportaron en promedios y medidas de dispersión, las de distribución no paramétrica se reportaron como frecuencias y porcentajes, la comparación de las variables cuantitativas se efectuó a través de la prueba de t de Student y U de Mann-Whitney según la distribución de los datos, para las variables cualitativas $\chi^{2}$ o exacta de Fisher. Un valor de $p<0.05$ se consideró significativo. Resultados: Setenta y seis pacientes, edad 48 (33.564), 51.3\% hombres. El BH fue de $247 \mathrm{~mL}(-568.5$ - 990). El BH fue negativo en $62.5 \%$ de pacientes con fracaso en PVE $p=0.36$. El BH positivo no tuvo influencia en el desenlace del retiro. Conclusiones: El BH positivo no es un predictor de fracaso para el retiro de la VM.

Incidencia de complicaciones y factores de riesgo en el traslado intrahospitalario del paciente crítico

Rabelo De la Torre Marisel, Canedo Castillo Nancy Allin, Esquivel Chávez Alejandro, Sánchez Suárez Juan Carlos, Zamora Varela Sergio

UMAE, Hospital de Especialidades «Dr. Antonio Fraga Mouret», CMN «La Raza». 
Objetivo: Determinar la incidencia de complicaciones y factores de riesgo en el traslado intrahospitalario de los pacientes críticos. $\mathrm{Pa}$ cientes y métodos: Se realizó un estudio prospectivo, observacional, en pacientes críticos que fueron trasladados a diferentes servicios durante su estancia en la $\mathrm{UCl}$ en el periodo comprendido de septiembre a diciembre de 2019. Resultados: De 146 traslados, se observó que 47 presentaron eventos adversos, los más frecuentes fueron hipertensión, agitación e hipotensión. Los factores de riesgo fueron SOFA > 8 y el puntaje TISS 28. Los pacientes quirúrgicos presentaron mayores complicaciones asociadas al traslado. La duración del traslado > 35 minutos se asoció con eventos adversos que afectaron a los pacientes con incremento de la mortalidad hasta de $36 \%$. Conclusiones: Este estudio confirma que el traslado intrahospitalario del paciente crítico puede generar un incremento en los eventos adversos. Estos hallazgos deberían generar una iniciativa para disminuir la incidencia de los mismos.

Utilidad de la excursión y el grosor diafragmático como predictores de fracaso en el retiro de la ventilación mecánica invasiva prolongada

Cuj Torres Álvaro, Arballo Imperial Leslie Alejandra,

Canedo Castillo Nancy Allin, Esquivel Chávez Alejandro,

Aguilar de los Santos Moisés Abraham

UMAE, Hospital de Especialidades «Dr. Antonio Fraga Mouret», CMN "La Raza».

Objetivo: Determinar que la excursión (ED) y el grosor diafragmático (GD) son predictores de fracaso al retiro de la ventilación mecánica prolongada (FRVMP) posterior a prueba de ventilación en pieza en T (PVT). Pacientes y métodos: Estudio prospectivo, en pacientes con FRVMP. Se midieron ED y GD por USG al final de la PVT. Se determinó la utilidad de la ED y GD mediante curva ROC, sensibilidad (S), especificidad (E) y valores predictivo positivo (VPP) y negativo (VPN). Una $p<0.05$ se consideró significativa. Resultados: 63 pacientes, edad promedio 54.2 años, $55.6 \%$ mujeres. Neumonía 46\%. El 23.8\% FRVMP. La principal causa de fracaso fue respiratoria (46\%). La ED y GD promedio tuvieron área bajo la curva ROC de 0.925. La ED promedio fue $>10.5 \mathrm{~mm}$ y el grosor diafragmático $<2.6 \mathrm{~cm}$, que tuvo S de $87.5 \%$, E de $80 \%$, VPP de $42 \%$ y VPN de $98 \%$ para predecir FRVMI. Conclusión: La ED y el GD por USG al final de la PVE pieza en $\mathrm{T}$, es útil como predictor de fracaso en el retiro de la VMI. El punto de corte de $10.5 \mathrm{~mm}$ en la ED y $<2.6 \mathrm{~cm}$ grosor diafragmático tiene adecuada sensibilidad y especificidad.

IMC mayor de 30 como factor de riesgo para retiro de VM prolongado en pacientes con SIRA por SARS-CoV-2

Medrano García Anabel

Hospital General "La Villa», Secretaría de Salud de la Ciudad de México, México.

Introducción: EI COVID-19 ocasiona SIRA, la obesidad, impacta en la ventilación mecánica y destete. Objetivos: Demostrar que el IMC se relaciona con destete exitoso e IMC mayor de 30 como mal pronóstico en SARS-CoV-2. Material y métodos: Estudio observacional, descriptivo, retrospectivo, del 1 mayo al 31 de diciembre de 2020; incluyó 59 pacientes, analizando variables: IMC, prueba PCR para SARS-CoV-2, peso, talla, y ventilación mecánica invasiva. Resultados: Mayor prevalencia en género masculino, mayor porcentaje de IMC mayor de 30, y días de estancia. El grupo más afectado fue de 40-59 años, identificando obesidad y fracaso del destete. Se observaron pacientes menores de 40 años con IMC mayor de 30 con más días de ventilación mecánica, $60 \%$ de población fueron obesos. Conclusiones: IMC mayor 30 aumenta el fallo en el destete de VM, la obesidad aumenta el destete fallido, IMC mayor de 30 aumenta riesgo de destete prolongado, y mortalidad en pacientes con SARS-CoV-2.

Índice neutrófilo-linfocito como predictor de mortalidad en pacientes con SARS-CoV-2

Urbina García Diana Patricia

Hospital General "La Villa» de la SS de la Ciudad de México.
EI COVID-19 es una enfermedad viral emergente, identificada en Wuhan, China, en diciembre de 2019. Objetivo: Conocer si el índice neutrófilo/linfocito es predictor de mortalidad en pacientes con COVID-19. Metodología: Estudio transversal ambispectivo, incluyó 83 pacientes con SARS-CoV-2 de la UCIA del Hospital General «La Villa» de mayo de 2020 a mayo de 2021. Se analizaron las variables edad, sexo, comorbilidades e índice neutrófilo/linfocito promedio al primer y tercer día de estancia hospitalaria. Resultados: De los 83 pacientes, $71.1 \%$ fueron hombres y $28.9 \%$ mujeres, la edad promedio para ambos fue de 50.16 años. El índice neutrófilo/linfocito promedio de fallecidos al primer día fue 20.81 y 24.18 al tercer día, las comorbilidades asociadas: obesidad, diabetes mellitus tipo 2 e hipertensión arterial. Se realizó estadística descriptiva y análisis de la curva ROC. Discusión: Zahorec en año 2001 describió que el índice neutrófilo/ linfocito fisiológico es menor a 5 y valores mayores a 6 se asociaban a incremento de la morbimortalidad. En este estudio el índice neutrófilo/ linfocito se encontró hasta cuatro veces más alto en pacientes con COVID-19. Conclusiones: Los resultados de este trabajo demuestran que el índice neutrófilo/linfocito es un buen predictor de mortalidad en pacientes con COVID-19.

Coinfección por patógenos bacterianos y tratamiento en pacientes hospitalizados por COVID-19 y su mortalidad en la UTI Ortiz Juárez Hugo Alejandro Hospital General «La Villa».

Introducción: Los informes sobre pacientes críticamente enfermos con COVID-19 describen un resultado desfavorable con una alta tasa de mortalidad, especialmente en aquellos que requieren ventilación mecánica invasiva. Debido a la gravedad inicial de estos pacientes críticamente enfermos junto con la complejidad de descartar una coinfección bacteriana asociada con hallazgos clínicos, biológicos o radiológicos, más de $50 \%$ de los pacientes críticamente enfermos con SARS grave fallecen. Objetivo: Demostrar cuáles son las coinfecciones por microorganismos bacterianos y su tratamiento en pacientes manejados en la UCI por neumonía grave por SARS-CoV-2, y su impacto en la morbimortalidad. Material y métodos: Se realizó un estudio descriptivo, longitudinal, ambispectivo. Se incluyeron todos los pacientes ingresados entre el 01 de mayo y el 31 de diciembre de 2020 y que actualmente se encontraban dados de alta con vida o habían fallecido durante la hospitalización. Resultados: De 95 pacientes con COVID-19, 66 (69.5\%) fueron hombres y $29(30.5 \%)$ fueron mujeres, con una edad media de 46 años. La duración promedio de la estancia en la UCI fue de 10 días, y al final del estudio 61 casos $(64.2 \%)$ fallecieron y sólo 34 pacientes (35.8\%) egresaron por mejoría. Las bacterias más comúnmente aisladas fueron A. baumanni, 26; Escherichia coli, 10; Pseudomonas aeruginosa, 6; S. epidermidis, 6; S. aureus, 4; K. pneumoniae, 3. Fallecieron 61 pacientes de 95, de los cuales 43 eran hombres y 18 eran mujeres. Discusión: Presentamos una serie de pacientes centrándonos en describir las coinfecciones adquiridas en el hospital en estos pacientes. Sorprendentemente, la coinfección por neumonía bacteriana en pacientes hospitalizados por COVID-19 fue mayor en comparación con las coinfecciones que se produjeron en pacientes con otras infecciones por virus respiratorios.

Riesgo de mortalidad por COVID-19 de los biomarcadores con mayor disponibilidad en un Hospital General de los Servicios de Salud del Estado de Puebla Marroquín Barrera Manuel Alejandro,

Camacho Becerra César, Macías Moreno Michelle, Camacho Becerra Carlos, Ortega Vargas José Luis Hospital General de Puebla «Eduardo Vázquez Navarro».

Introducción: Entre los biomarcadores asociados a mortalidad por COVID-19 destacan deshidrogenasa láctica (DHL) e índice neutrófilos/linfocitos por su disponibilidad. Li y colaboradores reportan DHL/ 
linfocitos > 345 como predictor de mortalidad con área bajo la curva (ABC) de 0.85 , sin suficientes reportes adicionales sobre su rendimiento. Objetivo: Establecer el riesgo asociado y capacidad de discernimiento para mortalidad de los biomarcadores más disponibles entre adultos hospitalizados por COVID-19 severo. Material y métodos: Se investigó la correlación estadística para $\mathrm{DHL}$, linfocitos, índice DHL/linfocitos e índice neutrófilos/linfocitos y se estableció el valor categórico de mejor capacidad de discernimiento y mayor riesgo para el desenlace estudiado entre estos biomarcadores. Resultados: Se analizaron 69 individuos con COVID-19 severo, resultando que $\mathrm{DHL}>444$ UI/L OR 5.5 IC 95\% 4.8-6.3, ABC 0.67; neutrófilos/linfocitos > 13 OR 5.4 IC95\% 4.8-6.2; ABC 0.70, DHL/ linfocitos > 383 OR 5.2 IC95\% 4.5-5.9; ABC 0.65, linfocitos < 1,100 cel/ $\mu \mathrm{L}$ OR 2.6 IC95\% 2.3.5-3.0; ABC 0.63. Discusión: Los puntos de corte y capacidad de discernimiento de los biomarcadores estudiados son congruentes a lo descrito en la literatura. El riesgo más elevado se estableció para $\mathrm{DHL}>444 \mathrm{UI} / \mathrm{L}$. neutrófilos/linfocitos $>13$ posee la mayor capacidad de discernimiento, mientras que el conteo de linfocitos $<1,100 \mathrm{cel} / \mu \mathrm{L}$ posee la mayor especificidad, $80 \%$.

Características clínicas de pacientes con obesidad y síndrome de distrés respiratorio agudo (SDRA) secundario a COVID-19 Ugarte Martínez Paulina, Villalobos Álvarez Víctor Hugo, Aguirre Sánchez Janet Silvia, Chaires Gutiérrez Rodrigo Centro Médico ABC

Introducción: En el SDRA secundario a COVID-19 la obesidad se asocia a peores desenlaces y mayor morbilidad, con menor mortalidad, fenómeno conocido como «paradoja del obeso». Objetivo: Describir las características clínicas de los pacientes con obesidad en ventilación mecánica invasiva y SDRA secundario a COVID-19 grave. Material y métodos: Estudio retrospectivo, descriptivo. Se incluyeron pacientes con obesidad y SDRA hospitalizados de marzo a diciembre de 2020. Se clasificaron con la escala OMS de obesidad, e incluimos características clínicas, parámetros de ventilación e inflamación. Resultados: De 218 pacientes, $76(34.8 \%)$ tuvieron IMC > 30, 72.3\% fueron hombres, con mediana de 33.9 de IMC, $56.5 \%$ con obesidad I. Los parámetros de ventilación fueron volumen tidal de $6.8 \mathrm{~mL} / \mathrm{kg}$ de peso predicho, PEEP promedio de $13 \mathrm{cmH}_{2} \mathrm{O}(\mathrm{DE} \pm 2)$, presión meseta $26 \mathrm{cmH}_{2} \mathrm{O}(\mathrm{DE} \pm 2)$ y presión de conducción de $13 \mathrm{cmH}_{2} \mathrm{O}$ con 14 días de ventilación ( $D E \pm 10$ ), estancia hospitalaria de 24 días $(\mathrm{DE} \pm 10)$. Los parámetros de inflamación mostraron IL-6 de $170 \mathrm{pg} /$ $\mathrm{mL}(\mathrm{RIQ}=65.5-309)$, dímero $\mathrm{D}$ de $1,189 \mathrm{ng} / \mathrm{mL}(\mathrm{RIQ}=760-1,868)$ y PCR $15 \mathrm{mg} / \mathrm{dL}(\mathrm{RIQ}=7.48-26)$. Mortalidad general de $4.12 \%$. Discusión: Los pacientes con obesidad tuvieron ventilación mecánica prolongada con elevados marcadores de inflamación; sin embargo, nuestra población se mantuvo dentro de las metas de protección pulmonar con menor mortalidad en comparación con la reportada a nivel internacional, sin diferencia estadísticamente significativa entre los grados de obesidad.

Eficacia de una intervención no farmacológica (antifaz y tapones auditivos) en la prevención del delirium en el paciente crítico

Padilla Olea Noricel, Sandoval Pinales Arely Bernice, Cano Oviedo Abraham Antonio, Canedo Castillo Nancy Allin,

Cuahutencos Escalera Aleixa Vianey

Hospital de Especialidades Centro Médico Nacional "La Raza", IMSS.

Objetivo: Describir la eficacia de la intervención no farmacológica (antifaz y tapones auditivos) en la prevención del delirium en el paciente crítico. Material y métodos: Estudio prospectivo, longitudinal, comparativo y abierto en una UCI de tercer nivel, del 1 de junio al 31 de octubre de 2020 . Se identificó a aquellos pacientes con estancia igual o mayor de 24 horas en $\mathrm{UCl}$ que cumplieron con los criterios de inclusión. Se formaron dos grupos y se realizó asignación aleatoria simple. Al grupo experimental se les proporcionaron medidas no farmacológicas (antifaz y tapones auditivos). Se colocaron los tapones y el antifaz a las 22:00 horas y se retiraron a las 06:00 horas; al grupo control se proporcionó solamente tratamiento habitual. Se aplicó a todos los pacientes la escala CAM-ICU cada 24 horas y al presentar una alteración cognitivo-conductual. Resultados: 153 pacientes en dos grupos: experimental (76) y control (77). El delirium se presentó en $19.6 \%$ de los pacientes en la $\mathrm{UCI}(n=30)$. La presencia de delirio fue mayor en el grupo control 23.3 vs $15.7 \%$ en el grupo experimental sin diferencias significativas $(p=0.23)$. Conclusiones: Las medidas no farmacológicas no disminuyen la incidencia del delirium en los pacientes críticos en la UCI.

Comparación de desenlaces en los pacientes con COVID-19 grave con y sin vacuna contra SARS-CoV-2. Estudio piloto Emeterio-Alcázar Jazmín Guadalupe,

Enamorado-Cerna Linda Vanessa, Baltazar-Torres José Ángel, Rivero-Sigarroa Eduardo, Domínguez-Cherit José Guillermo Instituto Nacional de Ciencias Médicas y Nutrición

«Salvador Zubirán», SSA. Ciudad de México.

Introducción: Se espera que las vacunas contra SARS-CoV-2 (VCSARS-CoV-2) disminuyan la incidencia de COVID-19 grave y su mortalidad. Sin embargo, no hay evidencia suficiente para confirmarlo. Objetivo: Comparar los desenlaces en pacientes con COVID-19 grave con y sin VC-SARS-CoV-2. Pacientes y métodos: Estudio retrospectivo en adultos con COVID-19 grave. Recabamos variables demográficas y clínicas y las comparamos entre pacientes con y sin VC-SARS-CoV-2. Los desenlaces fueron extubación exitosa, tiempos de ventilación mecánica, estancia en UTI y hospitalaria, y mortalidad. Las variables numéricas se expresan como promedio \pm desviación estándar o mediana con rango intercuartílico y se compararon con t de Student/U de Mann-Whitney. Las categóricas se expresan como porcentaje y se compararon con $\chi^{2} /$ Fisher, $p<0.05$ se consideró estadísticamente significativa. Resultados: Incluimos 44 pacientes, $68.2 \%$ hombres, edad promedio 51.5 años, 22 por grupo. La edad ( 59.5 vs $43.6 \%, p=0.001$ ) e hipertensión arterial (59.1 vs $27.3 \%$, $p$ $=0.033$ ) fueron significativamente mayores en vacunados. Los vacunados muestran menor frecuencia de extubación exitosa (59.1 vs $72.7 \%, p=0.340$ ) y mayor mortalidad (40.9 vs $27.3 \%, p=0.034$ ), sin diferencias estadísticamente significativas. No hubo diferencias estadísticamente significativas en el resto de las variables. Conclusiones: La vacunación contra SARS-CoV-2 no parece modificar el desenlace de los pacientes con COVID-19 grave.

Prevalencia de factores de riesgo para hipertensión pulmonar en pacientes con COVID-19 grave en ventilación mecánica (VM) en el Departamento de Medicina Crítica «Dr. Mario Shapiro»

Núñez González Pablo, Gaytán García Cristhian Josué,

Palacios Chavarría Adrián, Aguirre Sánchez Janet Silvia,

Chaires Gutiérrez Rodrigo

Centro Médico ABC.

Introducción: La hipertensión pulmonar (HP) es una enfermedad caracterizada por remodelación arterial y vasoconstricción, que conduce a insuficiencia cardiaca derecha. La prevalencia de HP en pacientes con COVID-19 es de 13\%. Desde el punto de vista ecocardiográfico, las recomendaciones internacionales la definen como presión sistólica de la arteria pulmonar (PSAP) $>40 \mathrm{mmHg}$ (sensibilidad de $90 \%$ y especificidad de 75\%). Los factores de riesgo (FR) son: $\mathrm{PaO}_{2} / \mathrm{FiO}_{2}<$ $150 \mathrm{mmHg}$, hipercapnia $\left(\mathrm{PaCO}_{2}>55 \mathrm{mmHg}\right)$, presión de distensión alveolar elevada (PDalv), neumonía, obesidad y tabaquismo. Objetivo: Determinar la prevalencia de los FR en pacientes con HP con COVID-19 grave. Material y métodos: Estudio transversal, retrospectivo, descriptivo. Se recabaron datos del expediente electrónico de marzo a diciembre de 2020. Se realizó cálculo de prevalencias. Resultados: De 218 pacientes con COVID-19 grave, al $68.8 \%$ se le realizó ecocardiograma y se analizaron 100 pacientes con PSAP elevada con COVID-19, la hipoxemia representa (90\%), hipercapnia (73\%), PDalv elevada (52\%), tabaquismo $(43 \%)$ y obesidad $(40 \%)$ 
Conclusión: La HP es altamente prevalente en pacientes con COVID-19 grave, el FR principal para HP en pacientes en VM con COVID-19 es la hipoxemia y la hipercapnia, ambas situaciones características de la COVID-19.

\section{Síndrome inflamatorio multisistémico relacionado} a infección por SARS-CoV-2 en el adulto

Baldenebro Munguía Alejandra, López Morán Héctor, Vargas Aguirre Tania, Sánchez Nava Víctor Manuel, Corres Collantes Jorge

Hospital Zambrano-Hellion, Tec Salud.

Introducción: Tras un año de evidencia clínica en COVID-19, se desarrolló una entidad clasificada como síndrome inflamatorio multisistémico relacionado a infección por SARS-CoV-2, caracterizado por los hallazgos clásicos de inflamación. Fiebre como rasgo cardinal y disfunción multiorgánica que no sólo involucra vía aérea, piel, mucosas y el corazón, sino que también afecta con frecuencia el tracto gastrointestinal y sistema nervioso central. Caso clínico: $\mathrm{Pa}$ ciente femenino de 33 años con padecimiento 10 días previos de faringitis y cervicalgia, fiebre, malestar general y alteraciones neurológicas. Con el antecedente de infección por SARS-CoV-2 15 días previos. Ingresa en estado de choque, rastreo cardiaco inicial con hiperrefrigencia miocárdica y alteraciones en la contractilidad global. Se inicia vasopresor, antibiótico de amplio espectro con sospecha de urosepsis. En paraclínicos hay leucocitosis y reactantes de fase aguda elevados. Se solicita USG de vías urinarias sin evidencia de absceso renal. Al ecocardiograma con evidencia de disfunción sistólica moderada del ventrículo izquierdo y fracción de eyección 37\%. En tomografía de tórax con patrón de vidrio despulido. Con requerimiento de inotrópico. Continúa con datos de falla orgánica múltiple, se inicia esteroide e inmunoglobulina intravenosa y anticuerpos antiDNA positivos con disminución de factores de complemento. Al día once posterior a inmunoglobulina, se egresa del área crítica. Discusión: La respuesta inflamatoria desmesurada que desencadena la enfermedad por SARS-CoV-2 causa un impacto directo en varios órganos, creando un síndrome de diversas manifestaciones, para lo que aún no se han designado criterios diagnósticos específicos, por lo que evidenciar estos casos guía al clínico sobre la evolución de esta entidad.

Correlación del delta de ácido úrico con

APACHE II como marcadores de severidad en pacientes con SARS-CoV-2 en la UCI

Pérez Fernández Oyuky, Mendoza Rodríguez Martín, Mendoza Portillo Elizabeth

Hospital General "La Villa».

Introducción: EI SARS-CoV-2 es un reto, del cual se busca identificar un nuevo marcador de severidad para valorar el pronóstico y la mortalidad. Objetivo: Correlacionar delta de ácido úrico con la escala de APACHE II y su asociación con la mortalidad en pacientes con SARS-CoV-2 tratados en la UCI. Material y métodos: Estudio longitudinal en Hospital General «La Villa», del 01/11/2020 al 31/03/2021, 71 pacientes con criterios de inclusión: género indistinto, PCR positivo para SARS-CoV-2, mayores de 18 años, expediente completo, se usó programa Excel versión 16.47.1 y programa SPSS versión 26, análisis de gráficos con prueba $\mathrm{R}$ de Pearson, desviación estándar, Spearman. Resultados y discusión: De los 71 pacientes, $69 \%$ fueron varones y $31 \%$ mujeres, edad promedio 54.35 años ( \pm 10.28$)$, ácido úrico al ingreso de $3.9 \mathrm{mg} / \mathrm{dL}( \pm 1.74)$, ácido úrico al egreso de $2.89 \mathrm{mg} / \mathrm{dL}( \pm 1.70)$, delta de ácido úrico promedio $1.077 \mathrm{mg} / \mathrm{dL}( \pm 1.59 \mathrm{mg} / \mathrm{dL})$, Apache II al ingreso de 18.35 puntos $( \pm 9.04)$, al egreso 22.95 puntos $( \pm 19.68)$, mortalidad global de $50.7 \%$, de los cuales $78.67 \%$ requirió ventilación mecánica y $21.12 \%$ no requirió. Se demostró la relación entre delta de ácido úrico con la mortalidad de los pacientes con SARS-CoV-2, con método Rho de Pearson, p significativa 0.004.
Asociación entre distensibilidad estática (CST)

pulmonar y mortalidad en pacientes con ventilación mecánica (VM) por infección por SARS-CoV-2

Herrera Lillian Jovana, Camarena Alejo Gilberto,

Ramírez Urizar Diego Andrés, Aguirre Sánchez Janet Silvia, Chaires Gutiérrez Rodrigo

Centro Médico $A B C$.

Introducción: Las características fisiopatológicas del síndrome de distrés respiratorio agudo (SDRA) asociado a COVID-19 difieren de otras patologías con SDRA, debido a la conservación parcial de la distensibilidad del sistema respiratorio a pesar de una hipoxemia marcada. Objetivo: Determinar si la CST pulmonar en los primeros 15 días de VM está asociada con la mortalidad en la unidad de medicina crítica (UCl). Material y métodos: Estudio de cohorte, prospectivo, unicéntrico. Con 218 pacientes ingresados que recibieron VM de marzo-diciembre de 2020. Se tomaron datos basales y pronósticos, dividimos grupos en supervivientes y defunciones. Se realizaron análisis t Student, prueba exacta de Fisher, suma de rangos de Wilcoxon y regresión no paramétrica de Kernel. Resultados: No hubo diferencias entre la Cstat del día uno de VM entre los grupos defunciones vs supervivientes, 37 (30-45) vs $34.5(26-42) p=0.110$. En regresión de Kernel en los 15 días de VM, se predicen mortalidades (\%) con Cstat iniciales de $20 \mathrm{~mL} / \mathrm{H}_{2} \mathrm{O}(45 \%), 40 \mathrm{~mL} / \mathrm{H}_{2} \mathrm{O}(13 \%), 60 \mathrm{~mL} / \mathrm{H}_{2} \mathrm{O}(8 \%)$ y $80 \mathrm{~mL} / \mathrm{H}_{2} \mathrm{O}(7 \%)$. Resultados independientes a escala de SOFA. Conclusión: Aunque las diferencias no fueron significativas en el día uno, las regresiones de Kernel predicen mayor mortalidad con disminución de Cstat, independiente de la escala de SOFA.

\section{Síndrome neuroléptico maligno por sobredosis de} olanzapina más miositis secundaria en paciente VIH positivo en el Departamento de Medicina Crítica «Dr. Mario Shapiro» del Centro Médico ABC

Herrera Parra Lillian Jovana, Camarena Alejo Gilberto, Gaytán García Cristhian Josué, Aguirre Sánchez Janet Silvia, Chaires Gutiérrez Rodrigo

Centro Médico $A B C$.

Introducción: La olanzapina como antipsicótico atípico tiene un buen perfil de seguridad. En caso de sobredosis, se caracteriza por hipertermia y múltiples síntomas neurológicos. No hay reportes sobre miositis en la serie de casos. Material y métodos: Masculino de 49 años VIH positivo, CD4 > 350 y PCR/VIH1 indetectable. Usuario de bictegravir/emtricitabina/alafenamida. Ingresó posterior a la ingesta de $1 \mathrm{~g}$ de olanzapina de liberación prolongada. Presentó síndrome neuroléptico maligno (SNM) y rabdomiólisis con resolución a las 96 horas. En el día 13 presentó incremento de volumen en compartimento antebraquial posterior izquierdo con dolor intenso y limitación de la función, confirmando miositis por resonancia magnética. Se descartó infección sistémica o trombosis venoarterial. Se administró manejo a base de esteroides, con resolución en el día 21. Resultados: La asociación de rabdomiólisis en SNM es frecuente, sin reporte de miositis en la literatura. La evolución fue favorable con manejo empírico con esteroides. Conclusión: La asociación de SNM con miositis por olanzapina es un cuadro raro, sospecharlo en pacientes con intoxicación por antipsicóticos debe ser considerado.

Asociación del balance hídrico $(\mathrm{BH})$ y la oxigenación en pacientes con COVID-19 en ventilación mecánica invasiva (VMI) por SIRPA, en el Departamento de Medicina Crítica «Dr. Mario Shapiro»

Del Mazo Montero Brenda, Bórquez López Yazmín Fabiola, Gómez García María Guadalupe, Aguirre Sánchez Janet Silvia, Chaires Gutiérrez Rodrigo

Centro Médico ABC.

Introducción: En pacientes con SIRPA, el BH positivo se asocia con $\mathrm{VMI}$, estancia en UCl y hospitalaria más prolongada y mayor mortali- 
dad. Las estrategias restrictivas mejoran el curso en la oxigenación. Objetivo: Describir la asociación entre el $\mathrm{BH}$ y la oxigenación en pacientes con COVID-19 en VMI. Material y métodos: Se incluyeron pacientes mayores de 18 años con COVID-19, desde mayo a julio de 2020 en VMI por SIRPA, se dividieron en dos grupos: G1 balance positivo ( $>1 \mathrm{~mL} / \mathrm{kg}$ en 72 horas), G2 balance negativo ( $<0 \mathrm{~mL} / \mathrm{kg}$ en 72 horas). Resultados: Fueron 103 pacientes, de los cuales 95 se incluyeron (52\% hombres). El BH del primer día con una mediana de 2,208 vs $484 \mathrm{~mL}$ en el tercer día. $\mathrm{G} 1 \mathrm{n}=58$ y $\mathrm{G} 2 \mathrm{n}=37$. La oxigenación en el primer día en $\mathrm{G} 1$ fue $\mathrm{PaO}_{2} / \mathrm{FiO}_{2}$ de $118 \mathrm{mmHg}$ y en $\mathrm{G} 2$ de $134 \mathrm{mmHg}(p=0.17)$. En el tercer día, la $\mathrm{PaO}_{2} / \mathrm{FiO}_{2}$ con $144 \mathrm{mmHg}$ en $\mathrm{G} 1$ vs $220 \mathrm{mmHg}$ en $\mathrm{G} 2$ con diferencia estadísticamente significativa $(p=0.000)$. Conclusión: El BH menos positivo en el día tres se asoció a una mejoría en la oxigenación.

\section{Efecto de levosimendán en la oxigenación en pacientes con} síndrome de distrés respiratorio agudo (SDRA) por COVID-19 Cruz Bolaños Hans de Jesús, Ramírez Urízar Diego,

Contreras Contreras Alma, Montes de Oca Marco Antonio, Aguirre Sánchez Janet Silvia, Chaires Gutiérrez Rodrigo Centro Médico ABC

Introducción: Levosimendán es un inodilatador con propiedades vasodilatadoras pulmonares que disminuye la poscarga del ventrículo derecho con consecuente mejoría en la perfusión y oxigenación, hasta el momento no hay estudios en COVID-19. Objetivo: Determinar el efecto de levosimendán sobre la oxigenación en pacientes con COVID-19 en ventilación mecánica invasiva (VMI). Material y métodos: Estudio observacional retrospectivo de marzo a octubre de 2020. Fueron 141 pacientes reclutados, 10 (7\%) con criterios de inclusión con SDRA y COVID-19 en VMI y uso de levosimendán en los primeros siete días de internamiento. Resultados: De 10 pacientes, siete fueron hombres, $30 \%$ con mejoría en la relación de oxigenación, $20 \%$ con disminución de cortocircuitos. No hubo diferencias significativas en $\mathrm{PaO}_{2} / \mathrm{FiO}_{2}$ después del uso de levosimendán. La mortalidad fue de $70 \%$. El grupo de mortalidad con APACHE II mediana de 24 (RIQ 18$30)$ vs 6 (RIQ 3-15), $p=0.033$. Sin variables clínicas o gasométricas asociadas a mortalidad. Discusión: Se observó mejoría en los parámetros de oxigenación, a pesar de que la mayoría tenían escala de APACHE II elevada. Existen varios factores que provocan hipoxemia de origen pulmonar o hemodinámico. El realizar estrategias sinérgicas es una meta que debemos considerar, por lo que el uso aislado de levosimendán no lleva a resultados benéficos.

Prevalencia de resistencia antimicrobiana en pacientes de una Unidad de Cuidados Intensivos en una unidad de tercer nivel Gutiérrez Tavares Mario, Zamora Varela Sergio,

Canedo Castillo Nancy Allin, Esquivel Chávez Alejandro, del Ángel Altamirano Karla

UMAE, Hospital de Especialidades, CMN «La Raza», IMSS.

Objetivo: Cuantificar la prevalencia de resistencia antimicrobiana en pacientes infectados en la Unidad de Cuidados Intensivos (UCI). Pacientes y métodos: Estudio retrospectivo, transversal, observacional y comparativo basado en informes de microbiología y cultivos de pacientes en $\mathrm{UCl}$ con infección documentada. Se registró el número de cultivos positivos, tipo de muestra, organismo aislado, sensibilidad o resistencia del organismo a cada antibiótico y antibióticos utilizados. Se midieron frecuencias y proporciones, de microorganismos, resistencia y susceptibilidad, se comparó con los datos reportados por Baltazar et al. en 2009 y en 2017. Resultados: Se recabaron 126 pacientes, $55 \%(n=70)$ hombres y $45 \%(n=56)$ mujeres. La edad promedio fue 54 años (RI 42-68). El puntaje promedio de SOFA al ingreso fue $8.46 \pm 3.68$ y APACHE II $16.13 \pm 5.16$. Los sitios de infección más comunes fueron intraabdominal $52 \%(n=41)$, pulmonar $37.1 \%(n=37)$ y urinario $19 \%(n=24)$. Los microorganismos frecuentes fueron $E$. coli (35.7\%), E. faecium, P. aeruginosa, $A$. baumannii y $S$. aureus. La mayor resistencia fue a penicilinas (80\%) cefa- losporinas (76\%) y fluoroquinolonas $(76 \%)$. A. baumannii fue el más resistente. Conclusiones: La resistencia antibiótica ha aumentado en los últimos años, destacan bacterias gramnegativas resistentes, particularmente $A$. baumannii.

Asociación entre la escala FRAIL, ventilación mecánica invasiva y mortalidad en pacientes críticamente enfermos Enríquez Barajas Christian Michel, Marín Rosales Miguel Hospital Civil de Guadalajara "Fray Antonio Alcalde».

Introducción: El índice de fragilidad puede establecer diferencias y obtener una estimación cuantitativa del grado de independencia y tener una capacidad pronóstica de predicción de mortalidad sin ser ampliamente explorada. Objetivo: Asociar la escala FRAIL en pacientes críticamente enfermos y su mortalidad hospitalaria en enfermos ancianos del servicio de MI del HGO. Material y métodos: Estudio transversal, analítico descriptivo en el HGO SSA; de mayo de 2019 a enero de 2020, hospitalizados en el servicio de MI, se aplicó escala FRAIL para detección y se dio seguimiento hasta el egreso. Resultados: Un total de 80 pacientes, mediana de 77 años, sexo femenino con $52.5 \%$. Cuatro grupos: 1 ) frágiles, en estado de choque que requieren $\mathrm{VMI}$; 2) frágiles en estado de choque sin $\mathrm{VMI}$; 3) frágiles no graves; y 4) no frágiles. La tasa de mortalidad fue de $71 \%$ para el grupo 1 , de $25 \%$ para el grupo 2 con un $R R=6.364$ y $R R=3.08$, respectivamente; en comparación con el grupo 3 y 4 . Conclusiones: La escala FRAIL correlaciona negativamente con las escalas de supervivencia y funcionalidad. Las escalas de mortalidad se asocian a frágiles graves y correlacionan positivamente; además, la mortalidad se eleva hasta seis veces respecto a los pacientes prefrágiles.

Efecto del óxido nítrico inhalado (ONi) en parámetros de oxigenación de pacientes con SIRPA grave por COVID-19 en ventilación mecánica (VMI) en el Departamento de Medicina Crítica «Dr. Mario Shapiro» Espinosa-Aznar Eduardo, Rugerio CabreraAndrea, Cruz Monzalvo Mónica, Chaires Gutiérrez Rodrigo, Aguirre Sánchez Janet Silvia Centro Médico ABC.

EI SIRPA por COVID-19 se asocia a mayor morbimortalidad. EI ONi se utiliza para hipoxemia refractaria con resultados controvertidos. Objetivo: Evaluar los efectos del ONi en los parámetros de oxigenación de pacientes con SIRPA grave por COVID-19. Material y métodos: Estudio de cohorte retrospectiva de marzo a diciembre 2020. Se incluyeron a todos los pacientes de acuerdo a los criterios de Berlín con SIRPA grave, refractario a estrategias convencionales. Se midieron los siguientes parámetros: presión arterial de oxígeno, saturación arterial de oxígeno, relación de $\mathrm{PaO}_{2} / \mathrm{FiO}_{2}$, gradiente alveolo-arterial (GA-a), cortocircuitos intrapulmonares (Qs/Qt). Resultados: Fueron 67 pacientes con ONi ( $p$ ) y VMI con una media de edad 62.7. Se evaluó la respuesta a las 24 horas con $40 \pm 20$ ppm. El ONi se mantuvo hasta su retiro con un promedio de duración de 7.3 días. Cuarenta por ciento presentó mejoría de la relación $\mathrm{PaO}_{2} / \mathrm{FiO}_{2}$ de $96 \pm 20$ a $180 \pm$ 20 (12\%); GA-a de $270 \pm 145$ a $173 \pm 167$ (35\%); Qs/Qt de $45 \pm 5$ a $35 \pm 5$. (5\%). Sobrevida $77.9 \%$ (52 p). Conclusión: El uso de ONi obtuvo respuesta favorable en los parámetros de oxigenación a las 24 horas de su aplicación.

Impacto de las infecciones asociadas a la atención de la salud en la mortalidad de pacientes con COVID-19 crítico Molina-Jaimes Aarón, Hernández-Guerrero Damaris, Cárdenas-Cantero Alejandro, Quijano-Soriano María Fernanda, González-Sánchez María del Carmen

Hospital Regional de Alta Especialidad, Bicentenario de la Independencia, ISSSTE.

Introducción: En México se cuenta con poca información sobre las infecciones asociadas a la atención de la salud (IAAS) en pacientes con COVID-19 crítico y si éstas son un factor de riesgo de mortalidad. Objetivos: Describir la mortalidad asociada a las IAAS en pacientes 
con COVID-19 crítico, los síndromes infecciosos y su microbiología. Material y métodos: Análisis retrospectivo, descriptivo y transversal de pacientes atendidos en la UTI-COVID-19 de marzo 2020 a junio de 2021 en un Hospital de Tercer Nivel. Resultados: 122 pacientes con COVID-19 crítico, 90\% requirieron VMI. Se detectaron 46 IAAS: $46.6 \%$ bacteriemia asociada a catéter, $31 \%$ infección urinaria asociada a sonda, $19.9 \%$ neumonía asociada a ventilación y $2 \%$ a infección de sitio quirúrgico. Los microorganismos identificados fueron: Gram negativos: Escherichia coli (22.8\%), Pseudomonas aeruginosa $(21.6 \%)$, Klebsiella pneumoniae $(8.7 \%)$, Acinetobacter baumannil $(5.2 \%)$ y Klebsiella oxytoca (1.7\%). Gram positivos: Enterococcus faecalis (10.6\%) Staphylococcus coagulasa negativos (15.7\%), Enterococcus faecium (5.2\%) y Enterococcus gallinarum (1.7\%). La mortalidad global pacientes con COVID-19 crítico fue de $52.1 \%$, la mortalidad de pacientes con IAAS fue de $50 \%$ y la mortalidad de pacientes $\sin$ IAAS fue de $46.6 \%(p=0.001)$. Discusión: Las IAAs en pacientes con COVID-19 crítico se asocian con un incremento en la mortalidad.

El uso del ultrasonido en el paciente con infección por COVID-19. Experiencia en un hospital de tercer nivel de atención Escobar Ortiz Diana, Hernández López Guillermo David,

Sánchez García Alejandro Osmar, Montes Cedillo Julio César, Cerón Juárez Raúl

Hospital de Ortopedia "Dr. Victorio de la Fuente Narváez", IMSS.

Introducción: El empleo del ultrasonido pulmonar en la pandemia por COVID-19 ha sido de ayuda para el diagnóstico, evaluación del grado de afectación y monitorizar la respuesta al tratamiento. Objetivo: Reportar los hallazgos obtenidos mediante el empleo del ultrasonido en pacientes con COVID-19 por el médico durante la pandemia por COVID-19 en el Hospital de Ortopedia del IMSS. Material y métodos: Se reportaron los hallazgos de pacientes con un CORADS 5 y 6 en el área COVID-19 del Hospital de Ortopedia en un periodo de cinco meses. Se realizaron USG pulmonares utilizando la escala LUS score y accesos venosos guiados por USG. Resultados: Se realizó un total de 376 USG pulmonares con base en las recomendaciones establecidas en el consenso 2012 de Volpicelli, encontrando los siguientes perfiles: perfil A:12, B1:120, B2:211, C:28; derrame pleural: cinco; se colocaron ocho accesos venosos centrales guiados por USG de manera exitosa, encontrando las siguientes complicaciones: hematoma 1 , neumotórax 0 , sangrado en sitio de punción 1 . Conclusiones: El uso del USG mostró ser una herramienta de gran utilidad para mostrar el deterioro de la enfermedad. La mayoría de los pacientes presentaron múltiples líneas $\mathrm{B}$, fueron el hallazgo más constante en COVID-19.

\section{Asociación entre la terapia con tocilizumab y desarrollo de neumonía asociada a la ventilación mecánica en pacientes con COVID-19 en el Departamento de Medicina Crítica «Dr. Mario Shapiro» Valencia Guzmán Patricia, Bernal Ríos Nora, Rugerio Cabrera Andrea, Aguirre Sánchez Janet Centro Médico ABC.}

Introducción: La neumonía asociada al ventilador (NAV) es la infección pulmonar en pacientes con ventilación mecánica invasiva (VMI) durante más de 48 horas, asociándose con prolongación de la VMI y la estancia hospitalaria. En pacientes con COVID-19 factores como el uso de terapias inmunomoduladoras, fármacos anti-IL6 aumentan el riesgo de NAV, con una estimación combinada de mortalidad de $42.7 \%$. Objetivo: Evaluar la relación entre el uso de tocilizumab y el desarrollo de NAV en pacientes COVID-19. Material y métodos: Estudio de cohorte, retrospectiva. Se revisaron expedientes clínicos de pacientes ingresados en el Departamento de Medicina Crítica «Dr. Mario Shapiro» de marzo a julio de 2020, seleccionando a los pacientes con sospecha de NAV. Resultados: Se analizaron 115 pacientes, $52 \%$ recibieron tocilizumab, de los cuales $50 \%$ presentaron NAV ( $p$ $=0.823$ ). Quince por ciento de los tratados con tocilizumab y NAV fallecieron. No se encontró diferencia significativa entre la mortalidad de los pacientes con o sin NAV tratados con tocilizumab (6 vs $1 ; p=$ 0.641). Conclusión: No existe asociación entre la administración de tocilizumab y el posterior desarrollo de NAV. En los pacientes con NAV la etiología fue secundaria a bacterias típicas y tampoco se encuentra asociación con la mortalidad.

SOFA versus APACHE II como predictores de ingreso y mortalidad en Unidad de Cuidados Intensivos en pacientes con SARS-CoV-2 Guzmán Vargas Ismael, Mendoza Rodríguez Martin Hospital General «La Villa».

Introducción: La importancia de realizar un ingreso bien seleccionado a Unidad de Cuidados Intensivos se debe a que los espacios disponibles en estas áreas de atención son limitados. Las escalas pronosticas y escalas de valoración como APACHE II y SOFA pueden brindar información en la decisión para el ingreso de un paciente a la Unidad de Cuidados Intensivos. Objetivo: Demostrar que las escalas APACHE II es mejor predictor de ingreso y mortalidad a la UCI de pacientes con SARS-CoV-2 en comparación con la escala SOFA. Material y métodos: El estudio es retrospectivo y descriptico; se realizó en el Hospital General "La Villa» (HGLV) de la Secretaría de Salud de la Ciudad de México durante mayo a diciembre de 2021. Resultados: En el análisis de curva ROC se demostró que ambas escalas, tanto APACHE II como SOFA tienen la misma sensibilidad y especificidad para predecir mortalidad en los pacientes. A pesar de diferir en algunas variables que utilizan no hubo diferencia.

Desenlaces clínicos de pacientes con

traqueostomía por COVID-19

Jasso Molina Juan Carlos, Enamorado Cerna Linda Vanessa,

Rivero Sigarroa Eduardo, Domínguez Cherit Guillermo,

Rodríguez Andoney José de Jesús

Instituto Nacional de Ciencias Médicas y Nutrición «Salvador Zubirán».

Introducción: Entre 5-10\% de los pacientes con infección por SARSCoV-2 requieren ventilación mecánica invasiva. La traqueostomía es un procedimiento que se realiza en pacientes con ventilación mecánica prolongada y su uso como método de destete se ha incrementado por la reciente pandemia. Objetivo: Comparar las características clínicas y los factores asociados a mortalidad en pacientes traqueostomizados por COVID-19. Material y métodos: Estudio retrospectivo que incluyó pacientes con neumonía por SARS-CoV-2 y traqueostomía entre marzo de 2020 a abril de 2021. Resultados: De 789 pacientes con ventilación mecánica, 68 (8.6\%) fueron traqueostomizados, 52\% fueron de abordaje percutáneo. La mortalidad global fue de $22 \%$ con una estancia hospitalaria de $48\left(\mathrm{RIC}_{25-75 \%} 40-63\right)$ días; 61 (89\%) pacientes recibieron ventilación en prono; 30 (44\%) requirieron gastrostomía y 17 (25\%) presentaron embolia pulmonar. Se encontró que la edad (vivos $54.5 \pm 13.4$ años vs finados $66.7 \pm 9.3$; OR 1.08 [ $\left.\mathrm{IC}_{95 \%} 1.02-1.14\right] \mathrm{p}=$ 0.0016 ) y el índice de masa corporal (vivos $30.9 \pm 6.7 \mathrm{~kg} / \mathrm{m}^{2}$ vs finados $26.9 \pm 6.6 \mathrm{~kg} / \mathrm{m}^{2}$; OR $0.15\left[\mathrm{IC}_{95 \%} 0.03-0.77\right] \mathrm{p}=0.023$ ) están asociados a mayor mortalidad. Discusión: La traqueostomía en pacientes con COVID-19 es un procedimiento seguro siendo la edad y el índice de masa corporal los principales factores vinculados con mortalidad.

Experiencia del uso de traqueostomía percutánea en pacientes con COVID-19 en el Hospital Español

Jiménez Báez Renato, Rentería Díaz Faustino Javier, Vidal Andrade Erick Rolando, Álvarez Maldonado Pablo Hospital Español.

La enfermedad por coronavirus 2019 (COVID-19) es un reto para los sistemas de salud. El principal desafío radica en identificar qué pacientes tienen más probabilidades de requerir ventilación mecánica prolongada y beneficiarse de la traqueostomía. Diferentes organizaciones propusieron que el momento de la traqueostomía en 
COVID-19 variaba de tres a 21 días. La recomendación actual es realizarla en los días 10-14 de ventilación mecánica invasiva, considerándose tardía. Los principales beneficios son: otorgar soporte ventilatorio en fase de recuperación, sedación mínima, lo que podría simplificar la atención. Objetivo: Describir los resultados con traqueostomía tardía en pacientes con COVID-19 en la unidad de terapia intensiva. Material y métodos: Estudio observacional descriptivo transversal en pacientes sometidos a traqueostomía tardía por insuficiencia respiratoria aguda por COVID-19. Resultados: 26 pacientes se sometieron a traqueostomía, el tiempo promedio desde la intubación endotraqueal hasta la misma fue $19.7 \pm 5.2$ días. Tiempo de retiro de ventilación mecánica: $11.4 \pm 2.4$ días. Puntaje SAPS II 38 \pm 11.3 puntos. Quince pacientes fueron egresados vivos (57\%). Discusión: En pacientes con síndrome insuficiencia respiratoria agudo grave por COVID-19, esperar 14 días de ventilación mecánica para realizar traqueostomía sigue siendo recomendación internacional.

Cuantificación de la congestión venosa por ultrasonido como predictor de mortalidad Tapia Cortez Giovanni Álvaro, Gasca Aldama José Carlos, Gutiérrez Toledo Karlos Dhamian, Hernández Lidia Mayo, Gómez Alayola Domingo José

Hospital Juárez de México.

Introducción: La congestión venosa está asociada a mortalidad, una forma de medirla es a través del VExUS Score, sin embargo, no hay antecedentes sobre el uso ecográfico (VExUS Score). Objetivo: Identificar el porcentaje de pacientes con congestión venosa al ingreso de Cuidados Intensivos del Hospital Juárez estimado por VExUS Score y su asociación con mortalidad. Material y métodos: Estudio observacional, retrospectivo y descriptivo en una muestra relacionada como única medición ultrasonográfica. Para las variables cualitativas se calcularon frecuencias y porcentajes. Para las variables cuantitativas continuas y discretas se utilizó t de Student para distribución normal y $\mathrm{U}$ de Mann-Whitney para libre distribución. Para variables categóricas y nominales se realizaron pruebas de $\chi^{2}$ de Pearson, para variables cuantitativas de libre distribución la medida de asociación fue mediana y rango intercuartil, el tipo de distribución se determinó mediante la prueba Shapiro-Wilk. Resultados: Pacientes con VExUS Score 2: $28.6 \%$ sobrevivieron y $71.4 \%$ fallecieron. En los pacientes no congestivos ( $N=16), 13(81.3 \%)$ sobrevivieron y $3(18.8 \%)$ no. Discusión: El VExUS Score es una herramienta rápida que determina congestión venosa y a su vez un punto de corte de $\geq 2$ está ligado a peor desenlace.

Traqueostomía en pacientes con COVID-19

en una Unidad de Terapia Intensiva

Reyes Pérez Amalia Angélica, Ramírez Gutiérrez Álvaro Eduardo,

Turrubiates Hernández Alexandro Theno, Azúa Guevara Reyna Isabel, Morales Hernández José Fernando

Hospital Regional de Ciudad Madero, Tamaulipas.

Introducción: La traqueostomía se realiza aproximadamente en $24 \%$ de pacientes de $\mathrm{UCI}$, tiene ventajas sobre intubación endotraqueal prolongada, en pacientes COVID-19 no está claro el rol de ésta. Objetivo: Describir tiempo de realización de traqueostomía, egreso, y días de ventilación mecánica invasiva (DVMI). Material y métodos: Estudio cohorte, descriptivo, retrospectivo del 1 de marzo al 30 de septiembre de 2021, incluyó pacientes mayores de 18 años con diagnóstico confirmado de SARS-CoV-2 a quienes se realizó traqueostomía percutánea (TP) o quirúrgica (TQ). Se recabó variables demográficas, indicación de traqueostomía: convencional o emergencia; tiempo de traqueostomía: temprano $<14$ o tardío > 14 días; técnica TP o TQ; resultados finales: egresó mejoría o defunción y DVMI. Estadística descriptiva, con cálculo de medidas de tendencia central y frecuencias. Resultados: Incluyó 13 pacientes, $84.6 \%$ género masculino, edad media $60.2 \pm 12.7$ años; las comorbilidades principales fueron hipertensión arterial (46.2\%) y diabetes (38.5\%); el $100 \%$ de los pacientes utilizó bloqueo neuromuscular y prono durante VMI; se realizó TP convencional al $84.6 \%$, se realizó TP tardía en $84.6 \%$ con una media de $26.2 \pm 13.3$ DVMI y $38.5 \%$ egreso por defunción. Discusión: En esta cohorte de pacientes se realizó TP tardía en 84.6 con $38.5 \%$ de egreso por defunción, con media de $26.2 \pm 13.3$ DVMI.

Comparación de la respuesta inflamatoria en pacientes críticos con infección por SARS-CoV-2 con presencia de lesión renal aguda al ingreso a $\mathrm{UCI}$

Maldonado Galeana Zuleima Berenice,

Guerrero Escobar Juan Carlos, Romero Gutiérrez Laura, Calleja Alarcón Salvador, Sánchez Hurtado Luis Alejandro UMAE Hospital de Especialidades « Bernardo Sepúlveda Gutiérrez» CMN Siglo XXI, IMSS.

Antecedentes: El virus SARS-CoV-2 se asocia con afección a diferentes sistemas además del respiratorio. Se ha observado la presencia de lesión renal aguda (LRA) e infección por SARS-CoV-2. EI objetivo de este trabajo es comparar la respuesta inflamatoria en pacientes críticos con infección por SARS-CoV-2 con o sin LRA al ingreso a UCl. Material y métodos: Estudio transversal, observacional, con sujetos con infección por SARS-CoV-2 y ventilación mecánica. A su ingreso a $\mathrm{UCl}$ se determinaron las concentraciones séricas de citocinas IL-1B, IL-6, IL 8, IL-10, FNT-alfa. El diagnóstico de LRA se hizo con los criterios KDIGO. Se dio seguimiento hasta el egreso de UCl. Resultados: Se reunieron 30 pacientes, 30\% tuvo LRA. La mortalidad global fue de 60 y $100 \%$ en el grupo con LRA. Las determinaciones de las citocinas IL-1B, IL6, IL8 no mostraron diferencias, La concentración sérica de IL-10 fue la única que mostró un incremento significativo en los sujetos con LRA $28.02 \mathrm{pg} / \mathrm{mL}$ IC 95\% (21.9541.63) vs $12.94 \mathrm{pg} / \mathrm{mL} \mathrm{IC} 95 \%$ (5.87-23.82) $\mathrm{p}=0.007$. Discusión: La respuesta antiinflamatoria mediada por IL-10 fue mayor en los sujetos con LRA y con mayor mortalidad. No se observó diferencia en las citocinas proinflamatorias en estos pacientes.

Relación entre niveles séricos de dímero $D$, extensión y patrón de daño pulmonar, evaluados mediante tomografía computarizada en pacientes con infección por SARS-CoV-2 Suárez Cuenca Juan Antonio, Flores Zaleta José Fernando, Corona Rojas Leslie Andrea, Guzmán Rullán Pablo,

Camacho Barajas Luis Alfonso

Corporativo Hospital Satélite, Estado de México, México.

Introducción: Algunos mediadores protrombóticos se han relacionado con la lesión pulmonar durante la infección por COVID-19. Objetivo: Evaluar la relación del dímero $D$ con la extensión y patrón de lesión pulmonar, determinada por tomografía computarizada, en pacientes con infección por COVID-19. Material y métodos: Estudio transversal analítico. Pacientes con PCR (+) COVID-19 atendidos en la UCl, «Corporativo Hospital Satélite» Ciudad de México de marzo a junio de 2020. Se incluyeron pacientes sin daño pulmonar previo, coagulopatía o uso de anticoagulantes. La extensión del daño tomográfico se evaluó con el software Image J. Resultados: Se incluyeron 104 pacientes, edad promedio 55 años, $66 \%$ hombres, quienes mostraron comorbilidades frecuentes de obesidad, hipertensión arterial sistémica y diabetes mellitus. El valor de dímero $D$ se relacionó con el área de afección tomográfica y las características cualitativas de la lesión pulmonar. El patrón de vidrio despulido se asoció a la edad, el sexo masculino y la elevación de mediadores proinflamatorios, mientras que el patrón tomográfico de consolidación se relacionó al índice de masa corporal. Discusión: El dímero $D$ se relacionó con la extensión y características de la lesión pulmonar, mientras que podría haber perfiles mediadores proinflamatorios y fenotipos antropométricos específicos para cada tipo de lesión.

Ancho de distribución eritrocitario como predictor de mortalidad en pacientes con SDRA severo por SARS-CoV-2 en UCI Hospital General «La Villa» Chávez Martínez José Alberto, Mendoza Rodríguez Martín Hospital General "La Villa», Secretaría de Salud, CDMX. 
Introducción: El síndrome de dificultad respiratoria aguda (SDRA) se define por la asociación de un inicio agudo de hipoxemia e infiltrados pulmonares bilaterales después de una agresión desencadenante. Existen muchos paraclínicos para dar pronóstico a los pacientes con esta entidad patológica. El ancho de distribución eritrocitario (ADE) es un marcador en la biometría hemática y se eleva en procesos sépticos. Objetivo general: Demostrar que la elevación del ancho de distribución eritrocitario se relaciona con mayor mortalidad en pacientes con SDRA por SARS-CoV-2 en UCI HG «La Villa». Material y métodos: Estudio descriptivo, longitudinal y ambispectivo, se incluyeron 110 pacientes con toma de biometría hemática de rutina al ingreso a UCl, se realizó un análisis sobre los niveles de ADE en un periodo comprendido de enero a junio del 2021. Resultados: Del total de los participantes, $67 \%$ fueron hombres con una edad media de 51.5 años, y $33 \%$ fueron mujeres con una edad media de 61.2 años. Se encontró que, del total, $74.3 \%$ eran diabéticos y $73.4 \%$ hipertensos. El $72.5 \%$ tenía SIRA severo y $27.5 \%$ moderado. El grado de severidad por SARS-CoV-2, con asociación entre HAS y el grado de severidad por SDRA (valor $p=0.015$ ); curva ROC con la concentración de ADE séricas para el pronóstico de mortalidad en pacientes con SDRA por SARS-CoV-2; el ADE es un indicador regular, utilizando el punto de corte $\geq 14.8 \%$, como pronóstico de mortalidad en pacientes con SDRA. La sensibilidad fue de $34.71 \%$ y una especificidad de $88.0 \%$, lo cual indica ser útil por su especificidad como indicador de severidad y mortalidad. OR 2.8 en asociación a muerte la elevación de ADE. Conclusiones: La elevación de $0.5 \%$ del valor basal del ADE aumenta el riesgo de mortalidad con una especificidad del $88 \%$. La elevación de ancho de distribución eritrocitario se eleva en neumonía por SARS-CoV-2.

Asociación entre el acoplamiento ventriculoarterial y el agua extravascular pulmonar indexada en pacientes críticamente enfermos

Gutiérrez Toledo Karlos Dhamian, Mayo Hernández Lidia, Gómez Alayola Domingo José, Tapia Cortéz Giovanni Álvaro,

Gasca Aldama José Carlos

Hospital Juárez de México.

Objetivo: Demostrar la asociación que existe entre el acoplamiento ventricular y el agua pulmonar extravascular. Material y métodos: Se revisaron expedientes de pacientes en la UCI del Hospital Juárez de México durante julio-diciembre 2018, que cumplieran criterios de inclusión; la información se recolectó en una base de datos. Se obtuvieron variables demográficas y hemodinámicas. Las características generales de la población de estudio se realizaron en programa SPSS. La distribución de datos se definió con U de Mann-Whitney para pruebas no paramétricas, determinando las diferencias estadísticas entre variables. La significancia estadística se estableció como una $p<0.05$. Resultados: Se encontró una correlación de variable día 2 EA con día 2 AVA, tiene una correlación fuerte con una R2 = 0.96. De acuerdo con la correlación de Pearson, se encontró una fuerte asociación con una R2 $=0.92$ entre días de estancia con días de ventilación mecánica. De acuerdo con una $\mathrm{n}=16$ pacientes, $50 \%$ no alcanzó la media de supervivencia. Discusión: El análisis hemodinámico con TDTP incluye tanto el ELWI como la determinación del acoplamiento ventrículo-arterial, está por definirse si optimizar estas variables repercute en mortalidad, en esta pequeña muestra no existe asociación entre ambas y los pacientes desacoplados tienen mayor mortalidad.

Prevalencia de delirium en pacientes obstétricas con infección SARS-COV-2 en una Unidad de Cuidados Intensivos

Díaz Juárez Victoria Adriana

Hospital General Regional No. 1 «Ignacio García Téllez» de Mérida, Yucatán, IMSS.

Las pacientes obstétricas tienen un mayor riesgo de contraer COVID-19 y, por lo tanto, requieren atención especial, la cual resulta extremadamente desafiante. Si bien el objetivo principal de COVID-19 son los pulmones, no se detiene allí. Los pacientes que requieren cuidados intensivos tienen más probabilidades de presentar comorbilidades y complicaciones subyacentes. Por lo que nos enfocamos en conocer la prevalencia de delirium en pacientes obstétricas con infección SARS-CoV-2. Se recabó la información de forma prospectiva y observacional de 23 pacientes obstétricas durante un periodo de 10 meses que ingresaron a la Unidad de Cuidados Intensivos (UCI). Se registró edad de $28.6 \pm 6.35$ años, $95.3 \%$ en puerperio quirúrgico, $34.8 \%$ con necesidad de ventilación mecánica (VM) durante $5.8 \pm$ 9.7 días de VM y $10.7 \pm 10.0$ días de estancia. Se diagnosticó delirium en $21.7 \%$ y ansiedad en $8.7 \%$. Otras complicaciones fueron trombosis (8.7\%), VM mantenida (13.0\%) y mortalidad (13.0\%). Algunas pacientes con COVID-19 pueden mostrar síntomas neurológicos inespecíficos, como delirium, que pueden preceder a los síntomas típicos, siendo más probable que consuman más tiempo del personal del hospital y valiosos recursos de UCl, tiempo-hospitalización y desarrollen mayores complicaciones. Resulta en una oportunidad para establecer el diagnóstico y manejo efectivo del delirium asociado con SARS-CoV-2.

Prevalencia de pacientes obstétricas con diagnóstico de COVID-19 con hipercalemia leve asociado al uso de enoxaparina en la UCIA Hospital General Regional No. 1 «Ignacio García Téllez» Inocente Argüelles Karina, Díaz Juárez Victoria Adriana Hospital General Regional No. 1 «lgnacio García Téllez».

Introducción: La tromboprofilaxis es un tratamiento usado en pacientes con COVID-19. Su uso prolongado, dosis altas y factores de riesgo agravantes en este tipo de pacientes han descrito la presencia de hipercalemia inducida por heparina/HBPM en 7 y $2.4 \%$, respectivamente. Objetivo: Determinar la prevalencia de pacientes obstétricas con diagnóstico de COVID-19 con hipercalcemia leve asociada al uso de enoxaparina en la UCIA del Hospital General Regional No. 1 «lgnacio García Téllez». Material y métodos: Se llevó a cabo un estudio descriptivo, retrospectivo observacional y trasversal; se incluyeron 23 pacientes obstétricas COVID-19, con tratamiento tromboprofiláctico (enoxoparina), hospitalizadas > 10 días y la relación con hipercalcemia leve en UCIA del Hospital General Regional No. 1 «Ignacio García Téllez», durante el periodo junio a octubre de 2021. Resultados: La media de edades en las pacientes obstétricas con COVID-19 fue de 28.2 . En $39.13 \%$ se mantuvieron hospitalizadas > 10 días, en todas se utilizó HBPM dosis profiláctica con factores de riesgo para COVID-19 (enoxaparina $1 \mathrm{mg} / \mathrm{kg} / 24 \mathrm{~h} />60 \mathrm{mg} / 24 \mathrm{~h}$ ), con DD mayor de $1,500 \mathrm{ng} / \mathrm{dL}$. Todas con un $\mathrm{K}$ en rangos normales, promedio de 4.2; día cinco el $\mathrm{K}$ aumentó en las pacientes con un promedio de 5.9 y para el día 10 disminuye en promedio a 4.8.

Cambios en las resistencias bacterianas en una unidad de cuidados intensivos antes y después de COVID-19 Lara Arroyo José Eliott, Hermosillo Ulloa Mariana Janeth, Rodríguez Cisneros Abraham

Centenario Hospital Miguel Hidalgo (CHMH).

Introducción: Las infecciones virales respiratorias predisponen a que los pacientes presenten coinfecciones, con un aumento de morbilidad, mortalidad y costos elevados de atención médica. La emergencia sanitaria de COVID-19 reveló las grietas en las respuestas de emergencia y atención de salud a nivel mundial, sin embargo, también ofrece importantes oportunidades para examinar los sistemas de salud e implementar medidas de control de infecciones para reducir la transmisión de bacterias resistentes a antimicrobianos. Objetivo: Describir los cambios en las resistencias bacterianas durante pandemia de $\mathrm{CO}-$ VID-19 en la Unidad de Cuidados Intensivos del Centenario Hospital Miguel Hidalgo. Material y métodos: Estudio retrospectivo descriptivo. Se realizó una revisión de todos los pacientes que ingresaron a la unidad de cuidados intensivos durante el periodo de tiempo mayo a octubre 2020. Resultados: Hubo modificación de las resistencias 
bacterianas con aparición de cepas MDR en E. coli y Pseudomonas aeruginosa. Discusión: No hubo cambio de resistencias en cuanto a la sensibilidad de vancomicina. Los días de estancia promedio en $\mathrm{UCl}$ fueron 18.87. La mortalidad dentro de la UCI durante COVID-19 fue de $57.1 \%$.

\section{Relación ELWI y PVPI como medida objetiva del SDRA y el impacto en la mortalidad a las 24, 48 y 72 horas en pacientes con COVID-19 de la Unidad de Terapia Intensiva Inocente Argüelles Karina \\ Hospital General Regional No. 1. "lgnacio García Téllez», IMSS.}

El síndrome de dificultad respiratoria aguda (SDRA) se caracteriza por exceso de agua pulmonar extravascular (ELWI) y aumento de la permeabilidad vascular pulmonar. En pacientes críticos con SDRA COVID es difícil evaluarlos. A través de la técnica de termodilución pulmonar (TDTP), se diagnostica objetivamente. Determinar el ELWI y PVPI como medida objetiva del SDRA tiene impacto en la mortalidad a las 24, 48 y 72 horas en pacientes con COVID-19. Estudio retrospectivo, transversal, observacional. Se incluyeron expedientes con método de TDTP, en el periodo de marzo a octubre de 2021 en la Unidad de Cuidados Intensivos. Se obtuvieron 13 expedientes con medición de ELWI/PVPI por TTP y se siguió a las 24, 48 y 72 horas. Se observó ELWI de $9.5 \mathrm{~mL}$ de forma inicial, $14 \mathrm{~mL}$ a las 24 horas, $y$ $12.56 \mathrm{~mL}$ a las 48 horas y $10.5 \mathrm{~mL}$ a las 72 horas. El iPVP inicial de $9.8 \mathrm{~mL} ; 12.6 \mathrm{~mL}, 19.6 \mathrm{~mL}$ y $18.4 \mathrm{~mL}$ a las 24,48 y 72 horas, respectivamente. Ocho de 13 pacientes que tuvieron ELWI $10 \mathrm{~mL}$ fallecieron a los 10 días pese al inicio del tratamiento temprano. EI ELWI y PVPI evalúan la gravedad e identifican SDRA en pacientes COVID, aquellos con ELWI > 10/IPVP > 3 tuvieron mortalidad de 100\% a 10 días.

Estimación matemática de la complacencia cerebral durante la aspiración de secreciones en el trauma severo de cráneo Carmona Suazo José Antonio, Ramos Suárez Ana Rosa, García Martínez Jesús, Jiménez Aguilar Rosalinda,

Amigo Oviedo Huizar Cristóbal León

Asociación Civil por la VIDA, Tecnológico de Estudios Superiores de Ixtapaluca, Centro Médico Nacional "La Raza" Unidad de Cuidados Intensivos Pediátricos IMSS, Secretaría de la Salud CENETEC.

Introducción: La complacencia cerebral (CC) se infiere por las cisternas de la tomografía. En México, la PIC se registra al final de la hora y no en forma continua. La tecnología actual permite contabilizar matemáticamente los cambios que se producen en la CC a pesar de PIC normal o alterada. Objetivo: Calcular el área durante la aspiración de secreciones (AS), estas mediciones pueden vigilar la evolución del paciente. Material y métodos: Después de recopilar los datos continuos del VT y PIC en una computadora personal, se tomó como inicio de la AS, la caída del VT, y se midió la PIC basal y como valor final de la PIC cuando ésta llegó al mismo valor inicial, al igual que para el VT. Se realizó la gráfica en Excel. Se llevó la gráfica al programa gratuito Wolfram Mathemática y se calcularon polinomios de grado 11, se calculó las derivadas de cada curva. Resultados: Las áreas de AS de cinco pacientes (20 aspiraciones) variaron considerablemente, la PIC máxima tardó en llegar a su valor inicial hasta 36 minutos. Discusión: Las áreas mayores y ángulos agudos de la PIC vs el tiempo sugieren mala CC.

Relación entre predictores de riesgo nutricional y severidad clínica en adultos con soporte nutricional endovenoso Marroquín Barrera Manuel Alejandro, Lira Marcial Ethel,

Macías Moreno Michelle, Cisneros Espinoza Lucero

Hospital General de Puebla "Eduardo Vázquez Navarro»

Servicios de Salud del Estado de Puebla.

Introducción: La relación entre predictores de riesgo nutricional (RN) y severidad clínica (SC) al iniciar la terapia de soporte nutricional endovenoso (SNE) ha sido poco reportada. Diversas escalas y biomarcadores estiman los grados individuales de RN y SV de la enfermedad. Objetivo: Reportar la capacidad pronóstica y coeficiente de correlación entre escalas y biomarcadores de RN y SC. Material y métodos: Se investigó el área bajo la curva $(A B C)$ para diferenciar mortalidad al egreso y la asociación bivariada, entre NUTRIC, IRN, NRS-2002, SAPS-II, SAPS-III, SOFA, APACHE-II, albumina, índice de masa corporal, colesterol total, aclaramiento de nitrógeno, linfocitos, e índice neutrófilos/linfocitos, en registros del departamento de nutrición clínica. Eliminamos las variables sin discernimiento y asociación. Resultados: De 165 participantes, el ABC fue significativa para SAPS-II (0.813), SAPS-III (0.795), SOFA (0.786), NUTRIC (0.762), APACHE-II (0.660), NRS-2002 (0.602), albúmina (0.771) y linfocitos (0.752). NRS-2002 relacionó moderadamente a APACHE-II $(\rho=0.657)$, NUTRIC relacionó moderadamente a SOFA $(\rho=0.603)$, SAPS-II $(\rho=0.598)$ y SAPS-III $(\rho=0.562)$. NRS-2002 relacionó débilmente a SOFA, SAPS-II y SAPS-III. Albúmina relacionó débilmente linfocitos, SOFA, SAPS-II y SAPS-III. Discusión: La capacidad pronóstica encontrada es congruente con la literatura al considerar las características de la población. NUTRIC y NRS-2002 asocian moderadamente $\mathrm{SC}$, con asociación débil para albúmina.

Asociación entre índice $\mathrm{PaO}_{2} / \mathrm{FiO}_{2}+\mathrm{PEEP}$ : incorporación de PEEP en el índice $\mathrm{PaO}_{2} /$ $\mathrm{FiO}_{2}$ y mortalidad en SDRA por COVID-19 Morales Hernández José Fernando,

Ramírez Gutiérrez Álvaro Eduardo, Sánchez Medina Jorge Rosendo, Turrubiates Hernández Alexandro Theno, Reyes Pérez Amalia Angélica Hospital Regional Pemex Cd. Madero.

Introducción: El índice $\mathrm{PaO}_{2} / \mathrm{FiO}_{2}$ está fuertemente asociado a mortalidad en síndrome distrés respiratorio agudo (SDRA). Es posible que incorporar PEEP al índice $\mathrm{PaO}_{2} / \mathrm{FiO}_{2}$ (P/FP) tenga más poder predictivo para muerte. Objetivo: Determinar asociación entre P/FP y mortalidad en pacientes con SDRA COVID-19 en UTI. Material y métodos: Diseño de casos y controles retrospectivo de pacientes ventilados con SDRA por COVID-19 de abril-septiembre de 2021. Dos grupos: (a) Sobrevivientes; (b) No sobrevivientes. Resultados: Se incluyeron 33 pacientes. El género masculino fue $75.8 \%(n=25)$, media de edad 55 ( $D E \pm 14)$. El grupo (a) de $57 \%(n=19)$, con $\mathrm{PaO}_{2} /$ $\mathrm{FiO}_{2}$ (24 horas) media (DE $\left.189.5 \pm 47.6\right), \mathrm{P} / \mathrm{FP}$ (24 horas) media (DE $212.5 \pm 108.9$ ), SOFA mediana 5 (IC 2-6). El grupo (b) de $42 \%(n=$ 14), con $\mathrm{PaO}_{2} / \mathrm{FiO}_{2}$ (24 horas) media (DE $199.8 \pm 44.3$ ), P/FP (24 horas) media (DE $198 \pm 115)$, SOFA mediana 5.5 (IC 2.7-7.5). Se realizó una correlación bivariada estadísticamente significativa para $\mathrm{DHL}(\mathrm{p}=$ $0.02)$, lactato (48 horas) $(p=0.02)$ y ferritina $(p=0.016)$. En la regresión logística binaria $\mathrm{PaO}_{2} / \mathrm{FiO}_{2}$ ni P/PF, ni el resto de las variables, excepto lactato (48 horas) (RM 0.084, IC-95\% 0.11-.62, $\mathrm{p}=0.011$ ) fue estadísticamente significativa. Discusión: Las diferencias entre $\mathrm{PAFiO}_{2}$ y P/FP no fueron estadísticamente significativas; aunque la $\mathrm{n}$ es pequeña con este estudio, no se descarta dicha asociación.

Ancho de la columna de aire laríngeo medida por ultrasonido, como predictor de estridor laríngeo postextubación Martínez Ayuso Francisco Agustín, Sánchez Montoya Felipe, Canedo Castillo Nancy Allin, Esquivel Chávez Alejandro, Uc Pérez Manuel Alejandro

UMAE, Hospital de Especialidades "Dr. Antonio Fraga Mouret», CMN «La Raza».

Objetivo: Estimar la asociación del incremento en el ancho de la columna de aire a nivel laríngeo, medido por ultrasonografía con el desarrollo de estridor laríngeo postextubación en el paciente con factores de riesgo. Pacientes y métodos: Se realizó un estudio prospectivo en pacientes con ventilación mecánica invasiva (VMI), con factores de riesgo para estridor laríngeo postextubación (ELPE), durante su estancia en la Unidad de Cuidados Intensivos (UCI). Se midió la diferencia del ancho de la columna de aire (DACA) por ultrasonido para determinar la asociación con la ocurrencia o no de estridor, se realizó un análisis de regresión logística univariado y multivariado, 
las variables se reportaron como riesgo relativo (RR) con intervalo de confianza del 95\% (IC95\%). Resultados: 84 sujetos durante el estudio, $57.1 \%(n=48)$ fueron mujeres. La edad promedio fue de 50.31 \pm 18.38 años. La frecuencia de ELPE fue del $10.7 \%$. Los sujetos con DACA $<1.47 \mathrm{~mm}$ mostraron estridor laríngeo con una sensibilidad de $100 \%$ y una especificidad de $97.33 \%$ área bajo la curva de 0.99 IC95\% (0.94-1.00) $p<0.0001$. Conclusiones: La DACA medida por ultrasonido fue menor en sujetos que mostraron estridor laríngeo. La DACA es un buen predictor de estridor laríngeo.

Factores de riesgo asociados a estridor laríngeo en pacientes con retiro de la ventilación mecánica en la terapia intensiva Facundo Bazaldúa Misael, Sánchez Hurtado Luis, Esquivel Chávez Alejandro, Canedo Castillo Nancy Allin, Ortiz Espinoza Lizbeth Guadalupe UMAE, Hospital de Especialidades "Dr. Antonio Fraga Mouret», CMN «La Raza».

Objetivo: Determinar si el sexo femenino, tiempo de intubación, reintubación, vía aérea difícil, obesidad y presión del globo de la cánula orotraqueal $>30 \mathrm{cmH}_{2} \mathrm{O}$ son factores de riesgo para desarrollar estridor laríngeo en pacientes a los que se les retira la ventilación mecánica en la terapia intensiva. Pacientes y métodos: Estudio prospectivo en pacientes con ventilación mecánica invasiva (VMI) por más de 24 horas continuas durante su estancia en la unidad de cuidados intensivos (UCl). Se realizó un análisis de regresión logística univariado y multivariado de las variables y se reportaron como riesgo relativo (RR) con su correspondiente intervalo de confianza de 95\% (IC95\%). Resultados: 117 sujetos, $53 \%(n=62)$ mujeres. La edad promedio del grupo de estudio fue de $49.52 \pm 17.62$ años, $39.3 \%$ eran obesos. La escala APACHE II fue de 14.5 puntos y un RIC de (10.25-20.00), SOFA de 8 y un RIC (6-10). La frecuencia de estridor laríngeo postextubación fue de $7.7 \%$. Ninguno de los factores de riesgo analizados mostró diferencia o asociación con la presencia de estridor laríngeo en este grupo de pacientes. La mortalidad fue de $18.8 \%$. Conclusiones: Los factores de riesgo no mostraron asociación con el desarrollo de estridor.

Incidencia y factores de riesgo para neumonía asociada a la atención a la salud (NAAS) adquirida en la Unidad de Cuidados Intensivos (UCl)

Arceo Rivas Adolfo, Ibarra Ortíz José Antonio,

Mita Campos Massiel Cristina, Esquivel Chávez Alejandro,

Salinas Amaro Itzel

UMAE, Hospital de Especialidades «Dr. Antonio Fraga Mouret», CMN «La Raza».

Objetivo: Describir la incidencia de la NAAS en la UCI y se evaluar la asociación de potenciales factores de riesgo para el desarrollo de NAAS. Pacientes y métodos: Se realizó un estudio observacional prospectivo en pacientes críticamente enfermos ingresados en una $\mathrm{UCI}$ de tercer nivel. Se registraron y analizaron las características demográficas y clínicas de los participantes. Se calculó la tasa de incidencia de NAAS y, mediante un modelo de regresión logística, se analizaron los potenciales factores de riesgo. Resultados: Revisamos los datos de 252 pacientes, 129 (51.2\%) fueron hombres, 29 (11.5\%) presentaron NAAS. Las transfusiones mostraron OR: 4.61 (IC95\%:1.70-12.49), $p=0.01$, el transporte fuera de la UCI OR: 4.61 (IC95\%: 1.76-12.06), $p=0.01$, y el uso de antibióticos profilácticos OR: 2.86 (IC95\%: 1.12-7.29), $p=0.02$. Conclusiones: La tasa de incidencia de NAAS en los pacientes críticamente enfermos es de $2.61 \%$ o 26 casos por cada 1,000 días de estancia en UCI. La transfusión de hemocomponentes, el transporte fuera de $\mathrm{UCl}$ y el uso de antibióticos profilácticos son factores pronósticos independientes en los pacientes críticamente enfermos para desarrollar NAAS.

Correlación del gap glucémico y el lactato sanguíneo en los pacientes sépticos: estudio observacional prospectivo de una cohorte
Perales Hernández José Guadalupe,

Sánchez Hurtado Luis Alejandro, Esquivel Chávez Alejandro,

Canedo Castillo Nancy Allin, Gómez Sánchez Edgar

UMAE, Hospital de Especialidades "Dr. Antonio Fraga Mouret», CMN «La Raza».

Objetivo: Determinar si el gap glucémico y el lactato sérico tienen correlación positiva en los pacientes sépticos al ingreso a Unidad de Cuidados Intensivos. Pacientes y métodos: Se realizó un estudio prospectivo en pacientes con choque séptico y sepsis al ingreso a la Unidad de Cuidados Intensivos. Se midió la hemoglobina glucosilada para registrar la glucosa media promedio, se registra glucosa al ingreso y el gap glucémico para asociación con la presencia o ausencia de hiperlactatemia. Resultados: Se realizó el análisis de correlación con la prueba de $\mathrm{R}$ de Pearson entre el gap glucémico y los diferentes momentos de medición de lactato. En la medición al ingreso de lactato se identificó una $r$ de $0.17 p=0.18$. Conclusiones: El gap glucémico no tiene correlación con los niveles de lactato en las primeras 24 horas.

Desenlaces clínicos en pacientes obesos

y no obesos con síndrome de insuficiencia

respiratoria aguda secundario a COVID-19

Enamorado-Cerna Linda Vanessa, Jasso-Molina Juan Carlos,

Fonseca-Lazcano José Antonio, Rivero-Sigarroa Eduardo,

Domínguez-Cherit José Guillermo

Instituto Nacional de Ciencias Médicas y Nutrición «Salvador Zubirán».

Introducción: Se ha demostrado que la obesidad es factor de riesgo independiente para desarrollar COVID-19 grave y requerir ventilación mecánica, sin embargo, no hay claridad en su efecto en mortalidad en UTI. Objetivo: Determinar la influencia de la obesidad en relación con desenlaces clínicos en una población con síndrome de insuficiencia respiratoria aguda por COVID-19. Pacientes y métodos: Estudio retrospectivo en adultos con COVID-19 grave que requirieron ventilación mecánica invasiva. Recabamos variables demográficas y clínicas comparándolas entre obesos y no obesos. Se observaron desenlaces en mortalidad, días de estancia y ventilación mecánica. Se utilizó regresión como variable dependiente a la mortalidad e independiente a obeso y no obeso; a partir de ello, se calculó Hazard Ratio. Resultados: Fueron 598 pacientes, $69.2 \%$ hombres, edad promedio 54 años, $51.3 \%$ obesos. Mortalidad en obesos y no obesos 30.9 y $39.5 \%$, respectivamente (p 0.02), HR $0.76(-0.1629,-0.0093)$. Sin diferencia estadísticamente significativa en días de estancia en UCI, $18.7 \pm 14.4$ versus $18.8 \pm 14.0$ ( $p$ 0.89) y días en ventilación mecánica, $17.1 \pm$ 12.1 versus $17.4 \pm 12.8$ ( $p$ 0.75). Conclusiones: La mortalidad es menor en los obesos, aproximadamente $25 \%$ con significancia estadística, sin embargo, no influye en días de ventilación mecánica o estancia en UTI.

Índices de oxigenación: comparando el pentágono

de la difusión alveolar, como predictores de

mortalidad en pacientes con COVID-19

Duran Pimentel Enid Georgina, Ramírez Salas Nery Denisse,

Cortes Román Jorge Samuel, Rivera Solís Gerardo,

Villegas Domínguez Josué Eli, Huanca Pacaje Juan Marcelo Hospital Regional ISSSTE Veracruz.

Introducción: Para mejorar la oxigenación, puede ser útil tener un índice para determinar la naturaleza de la deficiencia que está causando la insuficiencia respiratoria. Clínicamente, esta información ayudaría a hacer diagnóstico inicial podría ayudar a decidir si el paciente se beneficiaría de la admisión a la $\mathrm{UCI}$ en función de la probabilidad de revertir con éxito la afección. Material y métodos: Se realizó un estudio de cohorte prospectivo, se ingresaron a todos los pacientes con diagnóstico de infección por SARS-CoV-2 con prueba confirmada por PCR; en un periodo de tiempo comprendido del primero marzo a septiembre 2021 que ingresaron a Unidad de Cuidados Intensivos donde se correlacionó a los índices de oxigena- 
ción con el incremento de la mortalidad. Resultados: La población estudiada se compuso de 58 pacientes. $\mathrm{La} \mathrm{PAO}_{2}$, al ingreso de los pacientes que fallecieron, mostró media de $456.25 \pm 156.61$ ( $p=$ $0.5)$; se encontró que a las 72 horas de ingreso en los pacientes que permanecían con una $\mathrm{PAO}_{2}$ mayor de 426.87 era un factor de riesgo para mortalidad con una $p=0.01$. Encontramos que la $\mathrm{paO}_{2} / \mathrm{PAO}_{2}$ al ingreso de los pacientes que fallecieron presentaba una media $0.44 \pm 0.39(p=0.3)$, a las 72 horas una media de $0.24 \pm 0.13(p$ $=0.1$ ). Con respecto a la A-aDO2 se obtuvo que los pacientes que mantenían una media de $355.27 \pm 182.88$ presentaban mayor riesgo de mortalidad con una $p=0.02$. El Índice respiratorio que se obtuvo al ingreso de los pacientes que fallecieron mostró una media de $5.24 \pm 2.96(p=0.1)$. Conclusión: A diferencia de lo reportado en la población mundial, en nuestro estudio no encontramos diferencia o asociación significativa de los índices de oxigenación a su ingreso en UCI como predictor de mortalidad.

Asociación del delta del índice $\mathrm{DvaCO}_{2} / \mathrm{DavO}_{2}$ en las primeras 72 horas y la mortalidad en pacientes con choque séptico en la Unidad de Cuidados Intensivos Méndez de Jesús Ignacio Alberto, Gómez Flores Saira Sanjuana, Esquivel Chávez Alejandro, Canedo Castillo Nancy Allin, Alvarado Echavarría Alberto

UMAE, Hospital de Especialidades «Dr. Antonio Fraga Mouret», CMN «La Raza».

Objetivo: Determinar si el incremento de 10\% en el delta del índice DvaCO$/ 2 / \mathrm{DavO}_{2}$ en las primeras 72 horas se asocia con la mortalidad en pacientes con choque séptico en la Unidad de Cuidados Intensivos (UCI). Material y métodos: Estudio prospectivo, longitudinal, observacional y analítico en pacientes con choque séptico ingresados a la UCI. Se calculó el índice del delta $\mathrm{DvaCO}_{2} / \mathrm{DavO}_{2}$ para determinar el incremento o disminución a las 72 horas en dos grupos; los que incrementaron y los que no incrementaron el delta $\mathrm{DvaCO}_{2} / \mathrm{DavO}_{2}$ para determinar la asociación mediante el cálculo de razón de momios (OR), intervalo de confianza, $\chi^{2}$, t Student, un valor de $p<0.05$ se consideró significativo. Resultados: Se analizaron 45 pacientes, edad promedio $56.26 \pm 16.34$ años, de los cuales $60 \%$ fueron mujeres y $40 \%$ fueron hombres. La mortalidad fue de $44.4 \%$, se observó que el incremento de $>10 \%$ del índice $\mathrm{DvaCO}_{2} / \mathrm{DavO}_{2}$ tiene un OR de 59.63 IC 95\% 1.06-3353.05 $p=0.04$, ajustado a todas las demás variables confusoras para mortalidad en UCl. Conclusiones: El delta del índice $\mathrm{DvaCO}_{2} / \mathrm{DavO}_{2}$ es un factor de riesgo independiente de muerte en los pacientes con choque séptico dentro de las primeras 72 horas.

Trombocitopenia inmune trombótica inducida por vacuna SARS-CoV-2 en el embarazo

Dávila Zárate Josué Isaí, Novelo Pérez José Patricio, Vásquez Ramírez Roxana, Muñoz Ramírez María del Rosario Unidad Médica de Alta Especialidad del IMSS, UMAE 25. Monterrey, Nuevo León.

Introducción: La enfermedad por coronavirus 2019 se ha asociado con una importante morbilidad y mortalidad; la vacunación es el enfoque más prometedor para poner fin a esta pandemia. Se han notificado en todo el mundo alrededor de 50 casos de trombocitopenia y trombosis venosa relacionados con la administración de vacunas basadas en vectores adenovirales. Caso clínico: Mujer hispana de 25 años con 31 semanas de embarazo, sin enfermedades previas. Fue vacunada con la vacuna ChAdOx1 nCoV-19 (Astra Zeneca); unos días después desarrolló convulsiones tónico-clónicas, trombosis masiva de miembros superiores e inferiores y hemorragia intracerebral masiva. Se documentó un resultado positivo de ELISA contra factor plaquetario 4. Discusión: Esta nueva entidad se denomina TTIV (trombocitopenia inmune trombótica inducida por vacuna) causada por una de las dos vacunas COVID-19 de vector adenoviral. Se caracteriza por la presencia de factor plaquetario 4 , el cual no es dependiente de heparina. Conclusión: En un paciente con trombocitopenia y trombosis después de recibir vacunación contra COVID-19, esta condición debe sospecharse ampliamente. No se debe retrasar el tratamiento adecuado. Los beneficios de la vacunación superan con creces los efectos adversos poco frecuentes de la vacuna. 